\title{
Resolución, análisis y elaboración de tareas investigativas de geometría dinámica: saberes movilizados por profesores de matemáticas en formación continua
}

\author{
Rafael Enrique Gutiérrez Araujo ${ }^{1,2}$ \\ rafael.gutierrez0593@gmail.com \\ https://orcid.org/0000-0002-4003-8324 \\ Vinícius Pazuch ${ }^{1}$ \\ vinicius.pazuch@ufabc.edu.br \\ https://orcid.org/0000-0001-6997-1110 \\ ${ }^{1}$ Universidade Federal do ABC (UFABC, Brasil) \\ ${ }^{2}$ Asociación Aprender en Red (Venezuela)
}

Recibido: 15/05/2020 Aceptado: 06/07/2020

\begin{abstract}
Resumen
El objetivo del artículo es analizar la forma en la que un grupo de profesores de matemáticas, en un contexto de formación continua, moviliza saberes vinculados a la resolución, análisis y elaboración de tareas investigativas de geometría dinámica para la enseñanza en educación básica. Para ello, se empleó el modelo analítico de análisis de datos producidos en vídeo, desarrollado por Powell et al. (2004), el cual permitió identificar y examinar siete eventos críticos que ofrecieron información sobre cómo esos saberes fueron movilizados por diez profesores de matemáticas y un formador, mientras éstos se dedicaban a resolver un conjunto de tareas. Sustentado en los conceptos de saber y labor conjunta de la Teoría de la Objetivación (Radford, 2020), el análisis de los eventos críticos mostró el modo en que los participantes: (i) desarrollaron procesos de exploración, conjetura, experimentación y generalización, usando el software GeoGebra; (ii) identificaron acciones tecnológicas inherentes al trabajo con tareas de geometría dinámica y (iii) consideraron aspectos que caracterizan la exploración de esas tareas para su posterior elaboración. La interacción entre los participantes, así como las relaciones profesores-software y profesores-saberes fueron reconocidas como aspectos que influyeron en la forma cómo los saberes fueron movilizados en la investigación.
\end{abstract}

Palabras clave: Saberes profesionales; Formación de profesores; Objetos de aprendizaje.

\section{Resolução, análise e elaboração de tarefas investigativas de geometria dinâmica: saberes mobilizados por professores de matemática em formação continuada}

\section{Resumo}

O objetivo do artigo é analisar a forma como um grupo de professores que ensinam matemática, em um contexto de formação continuada, mobiliza saberes vinculados à resolução, à análise e à elaboração de tarefas investigativas de geometria dinâmica para o ensino de geometria na educação básica. Para tal, empregou-se o modelo analítico de análise de dados produzidos em vídeo desenvolvido por Powell et al. (2004), que permitiu identificar e examinar sete eventos críticos, os quais forneceram informação sobre como os saberes foram mobilizados por dez professores que ensinam matemática e um formador, enquanto se dedicavam a resolver um conjunto de tarefas. Subsidiada pelos conceitos teóricos de saber e labor conjunto da Teoria da Objetivação (Radford, 2020), a análise dos sete eventos 
críticos mostrou o modo em que os participantes: (i) desenvolveram processos de exploração, conjectura, experimentação e generalização, usando o software GeoGebra; (ii) identificaram ações tecnológicas inerentes ao trabalho com tarefas de geometria dinâmica e (iii) consideraram aspectos que caracterizam a exploração dessas tarefas para sua elaboração. Tanto a interação entre os participantes quanto as relações professores-software e professores-saberes foram reconhecidas como aspectos que influíram na forma como os saberes foram mobilizados na pesquisa.

Palavras-chave: Saberes profissionais; Formação de professores; Objetos de aprendizagem.

\title{
Resolution, analysis and elaboration of dynamic geometry investigative tasks: mathematics teachers' knowledge in a teacher education process
}

\begin{abstract}
The aim of the article is to analyze how a mathematics teachers' group, in a context of teacher education, mobilize their knowledge linked to the resolution, analysis, and development dynamic geometry investigative tasks for teaching geometry at middle and high school. The analytical model of data analysis produced in video developed by Powell et al. (2004), which made it possible to identify and examine seven critical events, which provided information on how the knowledge was mobilized by ten teachers who teach mathematics and a trainer, while dedicating themselves to solving a set of tasks. Subsidized by the knowledge theoretical concepts' and joint work of the Theory of Objectification (Radford, 2020), the analysis of the seven critical events identified showed the way in which the participants: (i) developed processes of exploration, conjecture, experimentation and generalization, using the GeoGebra software; (ii) identified technological actions inherent to working with dynamic geometry tasks and (iii) considered aspects that characterize the exploration of these tasks for their elaboration. Both the interaction between the participants and the teacher-software and teacher-knowledge relationships were recognized as aspects that influenced the way knowledge was mobilized in this research.
\end{abstract}

Keywords: Professional knowledge; Teacher education; Learning objects.

\section{Introdução}

$\mathrm{Na}$ literatura especializada a tarefa é um dos elementos principais da aula de matemática (Stein \& Smith, 2009). Em geral, sua importância no ensino de matemática tem sido destacada por diversos autores. Por exemplo, para Brocardo (2014), a tarefa é o instrumento que medeia o ensino e a aprendizagem, tornando-se uma temática relevante na educação matemática. Por essa e outras razões, as tarefas são fundamentais nas aulas de matemática, fato que "deveria ser motivo suficiente para que os professores fossem mais criteriosos quanto a sua seleção ou elaboração" (Cyrino \& Jesus, 2014, p. 752). Com efeito, a seleção ou elaboração de tarefas é considerada a decisão do professor de maior impacto nas oportunidades de aprendizagem matemática de seus alunos (Steele, 2001). É assim que a elaboração de tarefas matemáticas tem sido reconhecida como uma atividade específica do 
professor que ensina matemática, no momento de planejar a instrução (Delgado, 2014; Ponte, 2012; Serrazina, 2012).

Considerando o antes exposto, este artigo aborda a elaboração de tarefas matemáticas para o ensino, deixando claro que essa atividade supõe para o professor a construção integral de uma tarefa e não a sua adaptação de algum material curricular ${ }^{1}$. Particularmente, visa-se à elaboração de tarefas de investigação matemática, pois essas oferecem, entre outras coisas, a possibilidade de fazer matemática, no sentido de poder envolver-se em uma atividade que inclui exploração, elaboração, teste, reformulação e justificação de conjecturas matemáticas (Ponte et al., 2016).

No entanto, atualmente, as Tecnologias Digitais (TD) têm apresentado cada vez maior protagonismo no cenário educativo, particularmente, no ensino de matemática. Consequentemente, elas têm se tornado objeto de estudo por diversos pesquisadores em educação matemática nas últimas décadas (Rojano, 2014) e mais um elemento da atividade matemática da aula (Borba et al., 2018). No tocante ao tema curricular, as TD são reconhecidas por diferentes documentos curriculares oficiais como artefatos que oferecem possibilidades para desenvolver investigações matemáticas na aula (Brasil, 2017; NCTM, 2000). Assim, considerando a importância das TD no ensino de matemática, neste artigo adota-se a elaboração de Tarefas Investigativas de Geometria Dinâmica (TIGD) - tarefas de investigação matemática elaboradas com um Software de Geometria Dinâmica (SGD).

Esse interesse se sustenta nos resultados obtidos de uma revisão de literatura, realizada pelos autores, de pesquisas publicadas no período de 2008 a 2017. De um lado, revelou-se que as TIGD são o tipo de tarefa matemática que predomina em cenários de ensino de matemática - em contextos de ensino de geometria na educação básica e de formação continuada de professores - em que o SGD, como o software GeoGebra, é incorporado. Porém, de outro lado, revelou-se também a ausência de estudos centrados na forma em que professores que ensinam matemática elaboram TIGD e mobilizam saberes da sua profissão para tal fim. De acordo com Vieira et al. (2018), os professores que ensinam matemática mobilizam saberes da sua profissão quando se dedicam a planejar o ensino, no que tange à elaboração das tarefas que irão implementar na aula.

Diante desse panorama, pergunta-se: como professores que ensinam matemática mobilizam saberes próprios da sua profissão na elaboração de TIGD para o ensino? Uma

\footnotetext{
${ }^{1}$ Livros didáticos, direcionamentos curriculares sobre o ensino, etecetera.
} 
forma de responder essa pergunta é realizar pesquisas que coloquem o foco na maneira como esses saberes são mobilizados por professores que ensinam matemática, ao elaborar TIGD em contextos de formação continuada. Com efeito, Ponte (2003) destaca que a elaboração de tarefas investigativas não é um ato simples para os professores. Nesse sentido, de acordo com Serrazina (2012), os professores precisam de oportunidades para construir suas próprias tarefas para o ensino.

Com respeito a isso, acredita-se que uma forma de concretizar essas oportunidades, desde a formação de professores de matemática, é mediante o design e a implementação de atividades orientadas à elaboração de TIGD que integrem atividades de: (i) resolução de $T I G D$, (ii) análise de TIGD e (iii) elaboração de TIGD. De um lado, justifica-se a ideia de engajar os professores na resolução de TIGD já que, como afirmam Ponte et al. (2016), "ao envolver-se, ele próprio, a investigar situações matemáticas, o professor pode desenvolver ideias para propor aos alunos" (p. 143). De outro lado, considera-se que os professores devem analisar TIGD, uma vez que a análise de tarefas matemáticas constitui uma tarefa profissional do professor que ensina matemática para planejar o ensino (Prieto \& Valls, 2010). Portanto, a resolução e a análise de TIGD são consideradas nesta pesquisa como atividades que permitem criar condições para que os professores possam elaborar tarefas matemáticas para o ensino (Moretti \& Moura, 2011).

A partir disso, formula-se a seguinte pergunta de pesquisa: como um grupo de professores que ensinam matemática, em um contexto de formação continuada, mobiliza saberes vinculados à resolução, à análise e à elaboração de TIGD para o ensino de geometria na educação básica? No intuito de responder essa pergunta, estabeleceu-se como objetivo de pesquisa analisar a forma em que um grupo de professores que ensinam matemática, em um contexto de formação continuada, mobiliza saberes vinculados à resolução, à análise e à elaboração de tarefas investigativas de geometria dinâmica para o ensino de geometria na educação básica.

Para atingir esse objetivo, decidiu-se constituir uma lente teórica fundamentada nos conceitos de saber e labor conjunto da Teoria da Objetivação (TO) (Radford, 2020). Assim, a seguir serão discutidos esses conceitos. Na sequência, eles serão adaptados para o contexto da formação continuada de professores que ensinam matemática, orientada à elaboração de TIGD para o ensino. 


\section{Saber e labor conjunto: um olhar teórico}

Na TO, o saber é teorizado como uma síntese evolutiva culturalmente codificada de ação e reflexão (Radford, 2014). Nessa definição, a expressão síntese é usada para sugerir que o saber sintetiza a produção histórica de determinada questão pela atividade humana. Por sua parte, essa síntese é evolutiva porque está sempre em transformação (Radford, 2014). Finalmente, que tal síntese evolutiva seja culturalmente codificada significa que o saber pode ser pensado "como uma forma ideal de ações ... [que] vai além de cada uma de suas instâncias ou realizações concretas" (Radford, 2017c, p. 103).

A título de exemplo, imagine-se uma aula de matemática de educação básica, em que o professor solicita a seus alunos construírem um triângulo isósceles de lados $4 \mathrm{~cm}$ e $6 \mathrm{~cm}$ com régua e compasso. Como se pode notar, essa tarefa possui (pelo menos) duas soluções: (i) quando os lados congruentes do triângulo medem $4 \mathrm{~cm}$, (ii) e quando esses lados medem $6 \mathrm{~cm}$. Apesar de essas duas soluções serem diferentes, salienta-se que é possível aplicar uma mesma sequência de ações para obtê-las: (a) localizar o primeiro vértice $A$ do polígono em qualquer lugar do plano, (ii) desenhar uma circunferência com centro em $A$ e de raio alguma das medidas dadas, (iii) localizar o segundo vértice $B$ em qualquer lugar dessa circunferência, (iv) desenhar outra circunferência, dessa vez centrada em $B$ e de raio igual à segunda medida dada, (v) obter uma das interseções das duas circunferências, resultando no terceiro vértice $C$ e (vi) desenhar o triângulo $A B C$.

Para a TO, o que está por trás da sequência comum de ações descrita é um saber geométrico, constituído de forma histórica e cultural pela atividade humana. Especificamente, trata-se de um saber sobre a construção de um triângulo isósceles a partir de qualquer par de medidas, constituído ao longo do desenvolvimento da geometria euclidiana. Com efeito, o saber referido é uma síntese evolutiva culturalmente codificada de ação e reflexão sobre como construir triângulos isósceles com as características citadas, cuja origem provém dos Elementos de Euclides (Livro I, Prop. 22). Consequentemente, e conforme se pode observar, o conceito de saber da TO difere daquelas visões que o consideram como uma construção subjetiva da atividade do indivíduo (Radford, 2017c).

De acordo com Radford (2017b), o saber é mobilizado "apenas através de atividade sensorial cultural-histórica e pode entrar em existência sensorial apenas em e através da atividade" [ênfase adicionada] (p. 251). No contexto escolar, Radford (2020) salienta que "para aparecer [em sala de aula], o saber cultural deve ser posto em movimento pelos 
professores e estudantes. E a maneira de pô-lo em movimento, é através da atividade" [ênfase no original] (p. 26). Consequentemente, para a TO, o conceito de atividade é fundamental para entender a maneira como os saberes são mobilizados na experiência humana em geral e na sala de aula em particular. Na TO, a atividade é denominada como labor conjunto, teorizado como uma atividade de ensino-aprendizagem em que professores e alunos se empenham em conjunto, intelectual e emocionalmente, para produzir um trabalho comum (Radford, 2017b). Nessa definição, o conceito de trabalho comum faz referência ao resultado que professores e alunos produzem após engajar-se em um labor conjunto.

Nesta pesquisa interessa ressaltar dois aspectos do labor conjunto como conceito teórico. De um lado, destaca-se que essa atividade possui uma estrutura básica (Radford, 2017a), composta por: (i) o professor e seus alunos, (ii) uma tarefa matemática, (iii) um saber mobilizado enquanto essa tarefa é explorada, (iv) um conjunto de meios (signos e artefatos) usados para resolver a tarefa e (v) a produção de um trabalho comum, como resultado da atividade. De outro lado, enfatiza-se que o labor conjunto da aula é desenvolvido segundo um modelo composto por quatro momentos (Radford, 2017a), descritos na seção de metodologia, devido a suas implicações metodológicas na pesquisa.

\section{Resolução, análise e elaboração de TIGD como labor conjunto de formação docente}

Conforme mostrado inicialmente, a tarefa matemática é um aspecto central nesta pesquisa, definida como uma proposição que o professor realiza em sala de aula, buscando concentrar a atenção dos alunos em uma ideia matemática (Stein et al., 2009). Uma tarefa matemática é investigativa quando permite ao sujeito desenvolver uma atividade que inclui exploração, elaboração, teste, reformulação e justificação de conjecturas matemáticas (Ponte et al., 2016). Entende-se que uma tarefa investigativa é de geometria dinâmica (por exemplo, as TIGD) quando é preciso utilizar um SGD para desenvolver a atividade de investigação descrita, uma vez que o design da tarefa está em correspondência com o software que foi usado para elaborá-la (Borba et al., 2018).

Nessa linha, interessam aqueles contextos de formação continuada de professores de matemática, nos quais se convidam os professores a elaborar TIGD para o ensino de geometria na educação básica. Neste artigo, as TIGD possuem uma característica particular: para resolvê-las, é necessário explorar um Objeto de Aprendizagem (OA) elaborado com o software GeoGebra (Gutiérrez \& Pazuch, 2019). Um OA se define como um recurso virtual 
que pode ser usado e reutilizado em apoio à aprendizagem de uma ideia matemática, mediante interações na forma de simulações ou animações (Kalinke et al., 2015).

Levando em consideração o antes exposto, assume-se que uma formação de professores que ensinam matemática, orientada à elaboração de TIGD com essas características, compõe-se de três tipos de labor conjunto: (i) resolução de TIGD, (ii) análise de TIGD e (iii) elaboração de TIGD. A seguir será definido cada labor conjunto, bem como os saberes profissionais ou saberes para ensinar matemática (Valente, 2017) que são mobilizados nessas atividades formativas.

Em primeiro lugar, a resolução de TIGD é definida como um Labor Conjunto de Resolução (LCR), isto é, um labor conjunto em que um formador e um grupo de professores se empenham em conjunto, intelectual e emocionalmente, para produzir a investigação de uma propriedade geométrica. Na produção desse trabalho comum, formador e professores mobilizam um saber sobre como resolver TIGD. Nesta pesquisa, esse saber é definido como uma síntese evolutiva culturalmente codificada de ação e reflexão que implica o desenvolvimento de quatro processos matemáticos, quais sejam, explorar, conjecturar, experimentar e generalizar, usando SGD para a investigação de propriedades geométricas. Esses quatro processos, reportados por Christou et al. (2005) e explicados a seguir, constituem uma forma ideal em que tarefas de geometria dinâmica de cunho investigativo são resolvidas.

No primeiro processo (explorar), formador e professores exploram um OA para construir imagens da situação proposta na TIGD, ajudando-os a explorar visualmente essa situação e refletir sobre ela. No segundo processo (conjecturar), esses sujeitos estabelecem conjecturas sobre invariâncias geométricas que observam na reprodução do OA na tela do computador, após explorarem a situação inicial. Durante o terceiro processo (experimentar), formador e professores se dedicam a testar (confirmar ou negar) as conjecturas geométricas estabelecidas de forma experimental, usando para tal as ferramentas características dos SGD, como a medição e o arrastar de objetos geométricos (Arzarello et al., 2002). Finalmente, no quarto processo (generalizar), esses sujeitos realizam esforços para justificar as conjecturas testadas, tomando como base os saberes geométricos objetivados da geometria euclidiana, podendo concretizar provas formais, se for o caso (Marrades \& Gutiérrez, 2000).

Em segundo lugar, a análise de TIGD é definida como um Labor Conjunto de Análise (LCA), isto é, um labor conjunto em que formador e professores se empenham em 
conjunto, intelectual e emocionalmente, para produzir uma reflexão comum em relação com a natureza desse tipo de tarefa. Na produção desse trabalho comum se mobiliza um saber sobre como analisar TIGD, definido neste artigo como uma síntese evolutiva culturalmente codificada de ação e reflexão, que implica identificar as TIGD como tarefas de investigação matemática e tornar-se consciente tanto dos processos matemáticos envolvidos em sua resolução quanto das ações tecnológicas que caracterizam o uso de SGD para tal fim.

A definição desse saber fundamenta-se em dois referenciais teóricos. De um lado, ancora-se na classificação de tarefas matemáticas propostas por Yeo (2007), em que é definida uma ampla gama de tipos de tarefas segundo quatro critérios, quais sejam, a sua natureza, características, propósitos de ensino e possibilidades de avaliação. Assim, segundo o referido autor, analisar tarefas matemáticas considerando a natureza delas poderia resultar em uma variedade de tipos de tarefas, dentre elas tarefas: (i) procedimentais, (ii) práticas, (iii) de resolução de problemas, (iv) de proposição de problemas e (v) de investigação matemática. De outro lado, esse segundo saber se fundamenta no marco para a análise de tarefas de geometria dinâmica proposto por Trocki e Hollebrands (2018). Esse marco (desenvolvido para avaliar a qualidade de tarefas de geometria dinâmica) possui duas partes, relativas ao domínio matemático da tarefa e às ações tecnológicas que o sujeito executa para resolvê-la (Quadro 1).

Quadro 1: Marco para a análise de tarefas de geometria dinâmica

\begin{tabular}{|c|c|}
\hline \multicolumn{2}{|c|}{ Nível de profundidade matemática } \\
\hline Níveis & Descrição \\
\hline N/A & O prompt requer uma tarefa tecnológica sem foco na matemática. \\
\hline 1 & O prompt faz referência a um desenho que não possui fidelidade matemática. \\
\hline 2 & O prompt requer recordar um fato matemático, fórmula ou definição. \\
\hline 3 & O prompt requer considerar conceitos, processos ou relações matemáticas no desenho. \\
\hline 4 & O prompt requer explicar conceitos, processos ou relações matemáticas no desenho. \\
\hline 5 & $\begin{array}{l}\text { O prompt requer ir além da construção particular e generalizar conceitos, processos ou relações } \\
\text { matemáticas. }\end{array}$ \\
\hline \multicolumn{2}{|c|}{ Tipos de ações tecnológicas } \\
\hline Niveis & Descrição \\
\hline N/A & O prompt não requer desenho, construção, medida ou manipulação do desenho. \\
\hline A & O prompt requer desenhos dentro do desenho. \\
\hline $\mathrm{B}$ & O prompt requer medições dentro do desenho. \\
\hline $\mathrm{C}$ & O prompt requer construções dentro do desenho. \\
\hline $\mathrm{D}$ & O prompt requer arrastar ou utilizar outros aspectos dinâmicos do desenho. \\
\hline $\mathrm{E}$ & $\begin{array}{l}\text { O prompt requer uma manipulação do desenho que permita o reconhecimento de invariâncias } \\
\text { emergentes, relações ou patróes entre ou dentro de objetos geométricos. }\end{array}$ \\
\hline F & $\begin{array}{l}\text { O prompt requer a manipulação do desenho que possa surpreender quem explora as relações } \\
\text { representadas ou faça com que refine o pensamento com base em temas de surpresa que possam } \\
\text { se basear no teste de casos extremos. }\end{array}$ \\
\hline
\end{tabular}
Fonte: Adaptado de Trocki e Hollebrands (2018, p. 123) 
Como se pode observar no Quadro 1, cada parte do marco possui uma série de níveis vinculados à profundidade de cada domínio. Cada nível faz referência a um prompt, isto é, uma pergunta ou direção escrita relacionada a um desenho (na tela de um SGD) que requer uma resposta verbal ou escrita ${ }^{2}$ (Trocki \& Hollebrands, 2018). Para efeitos da posterior análise de dados, nesta pesquisa interessa colocar a atenção tanto nos processos matemáticos quanto nas ações tecnológicas a que cada prompt das tarefas implementadas faz referência, e não em estabelecer a sua qualidade (propósito do marco apresentado).

Por fim, a elaboração de TIGD é definida como um Labor Conjunto de Elaboração (LCE), isto é, um labor conjunto em que formador e professores se empenham em conjunto, intelectual e emocionalmente, na produção de uma TIGD para o ensino de geometria. Na produção desse trabalho comum se mobiliza um saber sobre como elaborar TIGD, definido como uma síntese evolutiva culturalmente codificada de ação e reflexão que implica ser consciente de que a tarefa a elaborar deve favorecer o desenvolvimento dos aspectos que caracterizam a exploração de tarefas matemáticas mediadas por TD, e considerá-los para tal fim. De acordo com Borba et al. (2018), tarefas matemáticas mediadas por TD devem favorecer, dentre outros, aspectos como: (i) geração de conjecturas matemáticas; (ii) criação e simulação de modelos matemáticos; (iii) manipulação dinâmica de objetos construídos; (iv) realização de testes de conjecturas usando um grande número de exemplos; (v) convencimento sobre a veracidade de conjecturas; (vi) elaboração de novos tipos de problemas e construções matemáticas; e (vii) exploração de diversas formas de resolução.

Considera-se que este referencial teórico aponta elementos para analisar a forma com que os três saberes de interesse da pesquisa são mobilizados por professores que ensinam matemática, quando esses participam de um processo formativo orientado à elaboração de TIGD para o ensino de geometria na educação básica.

\section{Metodologia}

\section{Pergunta, natureza e modalidade de pesquisa}

Conforme dito anteriormente, a pergunta diretriz que orientou o desenvolvimento da pesquisa é a seguinte: como um grupo de professores que ensinam matemática, em um contexto de formação continuada, mobiliza saberes vinculados à resolução, à análise e à elaboração de TIGD para o ensino de geometria na educação básica?

\footnotetext{
${ }^{2} \mathrm{O}$ leitor poderá notar, mais adiante, que as TIGD desta pesquisa estão estruturadas por prompts.
} 
Para responder essa pergunta, desenvolveu-se uma pesquisa qualitativa segundo os pressupostos de Bogdan e Biklen (1994). De acordo com esses autores, uma pesquisa qualitativa se caracteriza pelos seguintes aspectos: (a) a fonte direta dos dados é o ambiente natural; (b) a pesquisa é descritiva; (c) os pesquisadores se interessam mais pelo processo do que pelos resultados ou produtos; (d) tendem a analisar os seus dados de forma indutiva; e (e) o significado é de importância vital.

Segundo Fiorentini e Lorenzato (2012), a modalidade de uma pesquisa pode definirse em função de seus objetivos de investigação e de seu processo de produção de dados. Sobre o primeiro caso, a pesquisa é uma investigação descritiva, uma vez que em estudos dessa modalidade "o pesquisador deseja descrever ou caracterizar com detalhes uma situação, um fenômeno ou um problema" (p. 70). De acordo com o segundo caso, esta pesquisa é uma investigação de campo, considerando que nessa modalidade de pesquisa a produção de dados "é realizada diretamente no local em que o problema ou fenômeno acontece" (p. 71).

A seguir, apresentam-se os participantes e o contexto da pesquisa, assim como a forma com que os dados da investigação foram produzidos e analisados.

\section{Participantes e contexto de pesquisa}

Nesta pesquisa participaram dez professores que ensinam matemática nos Anos Finais do Ensino Fundamental e no Ensino Médio do Brasil. Durante o segundo trimestre de 2019, esses colaboradores participaram de um curso de extensão focado no tema de construções geométricas com o uso do software GeoGebra para a educação básica, oferecido em uma universidade federal da região metropolitana do estado de São Paulo, Brasil. O curso de extensão, orientado por um grupo de professores de matemática (dentre deles o primeiro autor da pesquisa, de agora em diante referido como $\mathrm{FP}^{3}$ ), foi desenvolvido em oito encontros realizados quinzenalmente com uma duração de três horas cada, distribuídos em três momentos: (i) familiarização com as ferramentas e as funcionalidades dinâmicas básicas do software GeoGebra, (ii) exploração de TIGD e (iii) análise pelos professores da implementação de TIGD em sala de aula.

Esta pesquisa coloca sua atenção nas atividades dos três encontros realizados no segundo momento da formação: a exploração de TIGD. Ao longo desses encontros, os

\footnotetext{
${ }^{3}$ Formador/pesquisador.
} 
participantes engajaram-se na exploração de três tarefas voltadas à resolução, à análise e à elaboração de TIGD, interagindo entre si de acordo com os quatro momentos do labor conjunto (Radford, 2017a). Fazendo a adaptação desse modelo ao caso do curso de extensão, no momento \# 1 de cada atividade FP apresentava a tarefa que teria de ser resolvida pelos professores. No momento \# 2, os professores se organizavam em pequenos grupos de três a quatro elementos para explorar a tarefa. No momento \# 3, FP visitava cada grupo para fazer perguntas aos professores, atender suas dúvidas, etc. Por fim, no momento \# 4, FP convidava os professores a apresentarem e discutirem o trabalho realizado, mediante discussão em plenária. Em função desse modelo, os professores organizaram-se em três grupos para explorar as tarefas propostas por FP, conformados da seguinte maneira: o grupo \# 1 foi composto por Júlia, Aleia e Jussara; o grupo \# 2, por Eduardo, Fábio e Joyce; e o grupo \# 3, por Mário, Carla, Katya e Anna ${ }^{4}$.

\section{Produção dos dados}

Os dados da pesquisa foram produzidos considerando o modelo de quatro momentos do labor conjunto (Radford, 2017a). Especificamente, decidiu-se registrar em vídeo e áudio o conteúdo dos fragmentos das atividades de LCR, LCA e LCE que correspondem aos momentos \# 2, \# 3 e \# 4 do modelo de labor conjunto. Com esses registros foi possível identificar o que Powell et al. (2004) chamam de eventos críticos: sequências conectadas de expressões e ações que fornecem informação significativa para responder questões de pesquisa. Assim, o conjunto de eventos críticos identificados nesta investigação forneceu informação significativa para analisar a forma com que os saberes sobre o modo de resolver, analisar e elaborar TIGD foram mobilizados pelos participantes, enquanto se engajavam na exploração das tarefas propostas. Logo, os dados da pesquisa provêm das transcrições desses eventos críticos.

Em algumas ocasiões, foi necessário consultar as produções escritas dos professores, no intuito de melhor compreender ou aprofundar o observado nos eventos críticos previamente identificados.

\footnotetext{
${ }^{4}$ Utilizaram-se nomes fictícios para proteger a identidade dos participantes.
} 


\section{Análise dos dados}

A análise dos dados foi realizada em três etapas. Na primeira etapa, identificaramse os eventos críticos nos registros em vídeo e áudio. Para tal, colocou-se a atenção nas formas de produção de saberes (Radford, 2020) dos participantes para produzir o trabalho comum das atividades de LCR, LCA e LCE. Especificamente, colocou-se a atenção nas formas com que eles: (i) desenvolveram os processos de explorar, conjecturar, experimentar e generalizar com SGD; (ii) identificaram esse tipo de tarefa como de investigação matemática e tornaram-se conscientes dos processos matemáticos involucrados em sua resolução e das ações tecnológicas correspondentes; e (iii) consideraram os aspectos que caracterizam a exploração de tarefas matemáticas mediadas por TD para elaborar TIGD. A identificação dos eventos apoiou-se em um instrumento como o ilustrado no Quadro 2.

Quadro 2: Instrumento para o registro dos eventos críticos identificados

\begin{tabular}{|l|l|l|l|}
\hline Encontro & Evento crítico & Registro (vídeo/áudio) & Observações \\
\hline & & & \\
\hline & \multicolumn{2}{|c|}{} \\
\hline
\end{tabular}

Fonte: Elaborado pelos autores (2020)

Na segunda etapa foi realizada a construção do enredo, isto é, o resultado da lógica dos dados, no intuito de "discernir uma narrativa emergente e evolvente sobre os dados ... [para o qual se] requer que o pesquisador proponha organizações criteriosas e coerentes dos eventos críticos" (Powell et al., 2004, p. 33). Assim, para a construção do enredo dos dados, incluiu-se uma quarta coluna no instrumento do Quadro 2, utilizada para realizar observações sobre o desenvolvimento dos eventos críticos, à medida que eram identificados. Essas observações permitiram, de um lado, agrupar em um mesmo evento crítico circunstâncias que tiveram lugar em momentos diferentes das atividades de LCR, LCA e LCE, e, de outro lado, compor uma primeira tentativa de narrativa dos dados, obtendo com isso uma organização relativamente coerente dos eventos críticos.

Finalmente, na terceira etapa examinaram-se as transcrições dos eventos críticos previamente identificados e organizados, em função: (i) da descrição do contexto de cada evento, de maneira que o leitor melhor compreenda as circunstâncias das falas dos participantes (Powell et al., 2004) e (ii) da interpretação do conteúdo dessas falas, à luz do referencial teórico descrito anteriormente.

Na seção a seguir, serão apresentados os resultados obtidos após realizar-se a análise descrita e decidir-se como esses resultados seriam comunicados. 


\section{Resultados}

Nesta seção reportam-se os resultados da pesquisa que permitem dar resposta à pergunta: como um grupo de professores que ensinam matemática, em um contexto de formação continuada, mobiliza saberes vinculados à resolução, à análise e à elaboração de TIGD para o ensino de geometria na educação básica?

Os resultados organizaram-se em três subseções, vinculadas à forma com que os participantes mobilizaram cada saber por separado. Assim, em cada subseção: (i) apresentam-se a tarefa explorada e os eventos críticos identificados, (ii) descreve-se o contexto das falas dos participantes em cada evento crítico, (iii) inserem-se os excertos dessas falas e (iv) interpretam-se esses excertos à luz do referencial teórico.

\section{Saber sobre como resolver TIGD}

Apresentam-se aqui os resultados obtidos após analisar a forma como os participantes mobilizaram o saber sobre como resolver TIGD, enquanto esses se engajavam na exploração da TIGD ilustrada na Figura 1. Essa tarefa teve por objetivo envolver os participantes na investigação da propriedade geométrica que relaciona as medidas dos ângulos consecutivos de todo paralelogramo, a partir da exploração de um $\mathrm{OA}^{5}$. Especificamente, a propriedade geométrica investigada foi a seguinte: os ângulos consecutivos de todo paralelogramo são suplementares.

Figura 1: TIGD explorada pelos participantes

$$
\begin{aligned}
& \text { O objeto de aprendizagem OA_01.ggb ilustra um paralelogramo que se divide em dois } \\
& \text { triângulos por uma das suas diagonais, através de uma animação desenvolvida ao clicar } \\
& \text { nos botões Iniciar, Continuar e Finalizar. Visualize atentamente a animação } \\
& \text { desenvolvida no recurso e responda as seguintes questões: } \\
& \text { a) O que você pode dizer sobre os quatro pares de ângulos consecutivos do } \\
& \text { paralelogramo? } \\
& \text { b) Justifique como você realizou a visualização dos ângulos consecutivos do } \\
& \text { quadrilátero na animação do OA para responder a questão anterior. } \\
& \text { c) Construa um paralelogramo ABCD usando uma nova janela do softuvare } \\
& \text { GeoGebra. Descreva o seu procedimento de construção. } \\
& \text { d) Descreva como usar a construção da questão "c" para ampliar as possibilidades de } \\
& \text { análise matemática da questão "a". } \\
& \text { e) Como você utilizaria a teoria geométrica, a partir da manipulação do software } \\
& \text { GeoGebra, para explicar as relações observadas? } \\
& \text { f) Realize as construções geométricas que permitam evidenciar as relações } \\
& \text { observadas na questão anterior. }
\end{aligned}
$$

Fonte: Elaborada pelos autores (2020)

\footnotetext{
${ }^{5} \mathrm{O}$ OA pode ser acessado no seguinte endereço eletrônico: https://ggbm.at/t9tzc59h.
} 
A seguir, apresentam-se os três eventos críticos que dão conta do modo como esse saber foi mobilizado pelos participantes no LCR desenvolvido.

\section{Evento crítico \# 1: Uso do OA para a visualização da propriedade geométrica}

O primeiro evento crítico dá conta da produção do grupo \# 1 de professoras, na tentativa de dar resposta às questões (a) e (b) da tarefa. Com respeito a isso, o Excerto 1 mostra o diálogo que FP estabelece com Jussara e Júlia, no qual essas professoras comunicam de que forma usaram o OA fornecido para responder a essas questões.

\section{Excerto 1}

1. FP (05:46-05:50): A primeira questão [da tarefa] é... [lê a questão]. Eles são? [referindo-se aos ângulos consecutivos do paralelogramo].

2. Jussara (05:51-05:52): Suplementares.

3. Júlia (05:53-06:00): Cada um deles, dois a dois. [Por exemplo], os ângulos $\angle A e$ $\angle B$ são suplementares.

4. FP (06:01 - 06:03): $\quad$ Ok, mas como o recurso ${ }^{6}$ ajuda a visualizar isso?

5. Jussara (06:04-06:22): Então, a gente falou isso na questão (b). A gente falou assim: esse mais esse mais esse [referindo-se aos ângulos do triângulo $\left.A^{\prime} B^{\prime} D^{\prime}\right]$ dá $180^{\circ}$, e aqui quando você gira esse daqui [refere-se ao triângulo $A^{\prime \prime} B^{\prime \prime} D^{\prime \prime}$ ], esse daqui [refere-se ao ângulo $\left.\angle D^{\prime \prime}\right] e ́$ coincidente com esse [refere-se ao ângulo $\angle D^{\prime}$ (Figura $2 \mathrm{~b}$ )].

6. Júlia (06:23-06:24): Congruente.

7. Jussara (06:25-06:38): Congruente, porque são sobrepostos. E a gente só escreveu assim: primeiro dá $180^{\circ}$ [a soma dos ângulos internos do triângulo $\left.A^{\prime} B^{\prime} D^{\prime}\right] \ldots$

8. Júlia (06:39-06:45): Por que a gente fez isso? Porque o $\angle A$ mais o $\angle B$ é igual do que...

9. Jussara (06:46-06:48): $\angle A^{\prime}$ mais $\angle B^{\prime}$ mais $\angle D^{\prime \prime}$ (Figura 2a).

No Excerto 1, Jussara comenta que os ângulos consecutivos do paralelogramo da tarefa são suplementares [2], em resposta ao questionamento de FP [1]. Em seguida, Júlia amplia a resposta da sua colega, ao explicitar que essa relação se aplica a cada par de ângulos consecutivos e relata, a título de exemplo, o caso dos ângulos $\angle A$ e $\angle B$ do polígono [3]. Diante da pergunta de FP sobre como o recurso ajuda a visualizar essa propriedade [4], as professoras respondem usando o caso dos ângulos $\angle A$ e $\angle B$. Nesse momento, Júlia e Jussara afirmam que a soma de $\angle A$ e $\angle B$ é igual à soma dos ângulos que, na Figura 2, são nomeados como $\alpha, \beta$ e $\gamma[8,9]$. Por sua vez, Jussara comenta que $\gamma$ é coincidente com o ângulo $\angle D^{\prime}$ (Júlia sugere usar o termo congruente [6]), após observar esse fato no giro do triângulo $A " B " D "$ na animação do OA [5]. Finalmente, as professoras estabelecem a conjectura

\footnotetext{
${ }^{6}$ No decorrer das atividades, os participantes utilizaram o termo recurso para referir-se aos OA.
} 
geométrica, ao afirmar que a soma dos ângulos do triângulo $A^{\prime} B^{\prime} D^{\prime}(\alpha, \beta$ e $\gamma$, Figura $2 \mathrm{~b}$ ) é igual a $180^{\circ}[5,7]$.

Figura 2: Relação entre $\angle A$ e $\angle B$ por meio dos ângulos $\alpha, \beta$ e $\gamma$

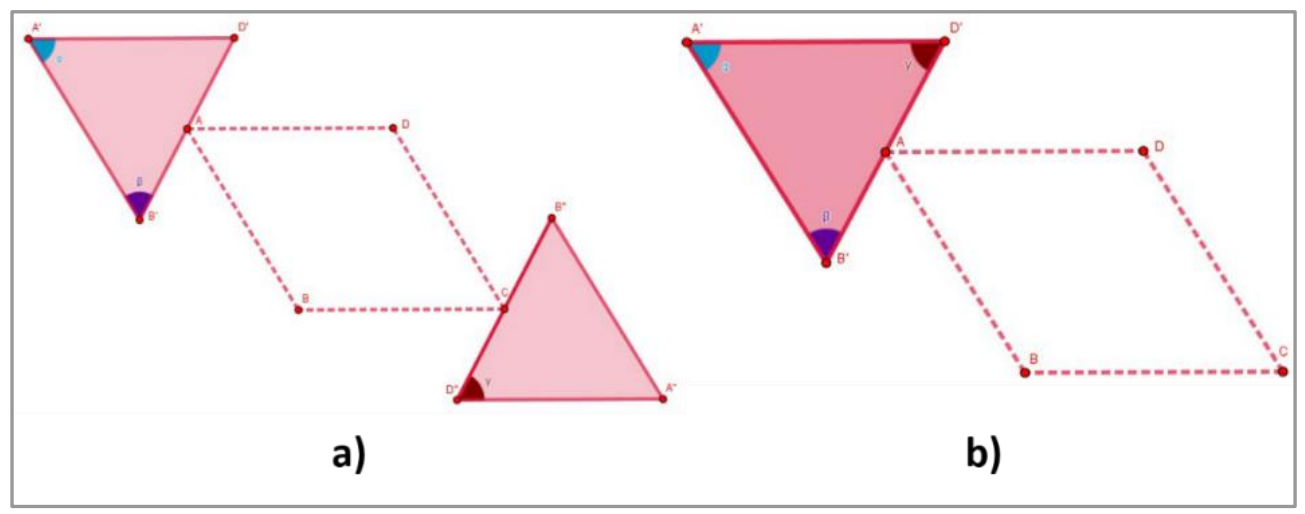

Fonte: Adaptada de Gutiérrez \& Pazuch (2019)

A forma com que o grupo \# 1 usou o OA para responder às duas primeiras questões da tarefa revela que o saber sobre como resolver TIGD foi mobilizado, no tocante aos processos matemáticos explorar e conjecturar. Aliás, destaca-se que ambos os processos foram desenvolvidos em sintonia, simultaneamente ao uso do recurso dinâmico. Com efeito, os dados mostram que o processo de formular a conjectura geométrica $[5,6,7,8,9]$ foi desenvolvido à medida que as professoras exploravam o $\mathrm{OA}$ da tarefa e recebiam respostas visuais da animação desse recurso (Figura 2).

\section{Evento crítico \# 2: Não uso do OA para a visualização da propriedade geométrica}

Em contrapartida, o segundo evento revelou que alguns professores não utilizaram o OA para iniciar a investigação geométrica da tarefa. Em outras palavras, evidenciou-se que as respostas dos professores às questões (a) e (b) da tarefa não foram decorrentes da visualização da animação do OA. No tocante a essa situação, foram identificados dois casos: o primeiro deles corresponde ao grupo \# 2 e o segundo, ao grupo \# 3.

No Excerto 2, FP visita o grupo \# 2 com o intuito de conhecer o que até aquele momento do LCR os professores desse grupo tinham feito para resolver a tarefa proposta.

\section{Excerto 2}

1. FP (00:30-00:36): Segundo o que o recurso mostra, como poderíamos responder essa pergunta? [refere-se à questão (a) da tarefa].

2. Eduardo (00:39-00:43): Se eles [referindo-se aos ângulos do paralelogramo] são consecutivos, eles vão formar $180^{\circ}$.

3. FP (00:45-00:48): E será que é possível observar isso no recurso?

4. Eduardo (00:50-00:53): Temos que verificar se o recurso possibilita isso. 
5. Fábio (00:55-01:02): Eu acho que possibilita por causa do conhecimento que a gente tem sobre os ângulos de um triângulo.

6. FP (01:03-01:10): Mas eu quero ver isso aí [refere-se ao recurso]. Me explica isso aqui [no recurso]. Essa ideia é boa, mas eu quero ver como o recurso mostra isso [refere-se à propriedade geométrica].

7. Joyce (01:11 - 01:00): Como eles são dois triângulos com lados iguais, a soma dos três ângulos internos é igual a $180^{\circ}$.

No Excerto 2, FP pergunta aos professores sobre como a questão (a) da tarefa pode ser respondida, em função da animação do OA [1]. Insiste novamente nisso [3], até expressar o seu desejo de que o apontado por eles possa ser visualizado no OA [6]. No entanto, os professores oferecem respostas que não são decorrentes do uso do recurso. O primeiro a se manifestar é Eduardo, que salienta que a soma das medidas dos ângulos consecutivos do paralelogramo deve ser igual a $180^{\circ}$ [2]. Posteriormente, Fábio, perante o comentário de Eduardo sobre o dever de verificar se o OA possibilita o que foi dito por ele [4], manifesta que isso seria possível pelo conhecimento que eles possuem sobre os ângulos internos de um triângulo qualquer [5]. Mais adiante, Joyce amplia a ideia de Fábio, ao sugerir que a soma das medidas dos ângulos internos dos triângulos que compõem o paralelogramo da tarefa é igual a $180^{\circ}$, sem estabelecer conexão entre esse fato geométrico e a ideia dos ângulos consecutivos desse quadrilátero, supondo na sua fala que os lados desses triângulos são congruentes [7].

De acordo com a informação do Excerto 2, pode-se observar que o saber sobre como resolver TIGD foi mobilizado parcialmente. De fato, os dados mostram que os professores não desenvolveram o processo matemático de explorar, uma vez que a conjectura estabelecida por Eduardo [2] não foi o resultado de utilizar o OA, senão do conhecimento geométrico prévio que eles possuíam [5]. Com efeito, Joyce desenvolve o processo de generalizar no momento de responder à questão (b) da tarefa, "pulando" o processo de experimentar, na medida em que tentou justificar o dito por Eduardo, recorrendo a uma explicação voltada ao plano teórico, e omitiu o uso do OA para tal [7].

No que diz respeito ao segundo caso, e procedendo da mesma forma que no primeiro, FP visita o grupo \# 3 para conhecer sua produção até esse momento do LCR (Excerto 3). 


\section{Excerto 3}

1. FP (10:09 - 10:21): Gostaria de saber o trabalho de vocês. Só um resumo. Qual a relação entre os ângulos consecutivos desse paralelogramo?

2. Carla (10:22 - 10:23): Os [ângulos] consecutivos são suplementares.

3. FP (10:24-10:37): Ok. Concordamos que sabemos isso pelo fato de ser professores. Agora, o meu interesse não é verificar se vocês sabem essa propriedade geométrica ou não, senão como o recuso ajuda a visualizar isso. Quem me explica como o recurso ajuda a visualizar essa propriedade?

4. Carla (10:38 - 10:39): Aqui, oh! [indica o seu caderno de notas (Figura 3)].

O Excerto 3 mostra um diálogo entre FP e Carla, que fala representando o seu grupo. O diálogo é iniciado por FP que, em seu desejo de conhecer o trabalho dos professores, pergunta qual a relação entre os ângulos consecutivos do paralelogramo da tarefa [1], e Carla, de maneira similar a Eduardo (Excerto 2), responde que esses ângulos são suplementares [2]. Perante essa resposta, FP supõe que esse saber é compartilhado por eles, devido ao fato de serem professores que ensinam matemática, mas expressa que o seu interesse está na forma como a propriedade geométrica pode ser visualizada no OA, e não em verificar se eles possuem o saber geométrico abordado [3]. Quando FP questionou como o recurso ajuda a visualizar tal propriedade [3], Carla respondeu mostrando-lhe algumas notas que ilustram a resposta que o seu grupo forneceu à questão (b) da tarefa [4].

O "problema" dessa resposta à questão (b) da tarefa (Figura 3) radica no fato de que a justificação da conjectura estabelecida [2] está baseada em um raciocínio que não acompanha o desenvolvimento da animação do OA. De fato, a Figura 3 mostra como o discurso dos professores está fundamentado em uma análise geométrica realizada na região interna do paralelogramo $A B C D$, e não na animação que envolve os dois triângulos visualizados. Aliás, chama a atenção o fato de os professores terem utilizado a ilustração gráfica que se visualiza na Figura 3, apesar de não corresponder visualmente ao discurso escrito - por exemplo, no relato dos professores indicam-se elementos do polígono que não estão desenhados, como a diagonal $\overline{B D}$ e o ângulo $\angle A D B$. 
Figura 3: Resposta do grupo \# 3 à questão (b) da tarefa

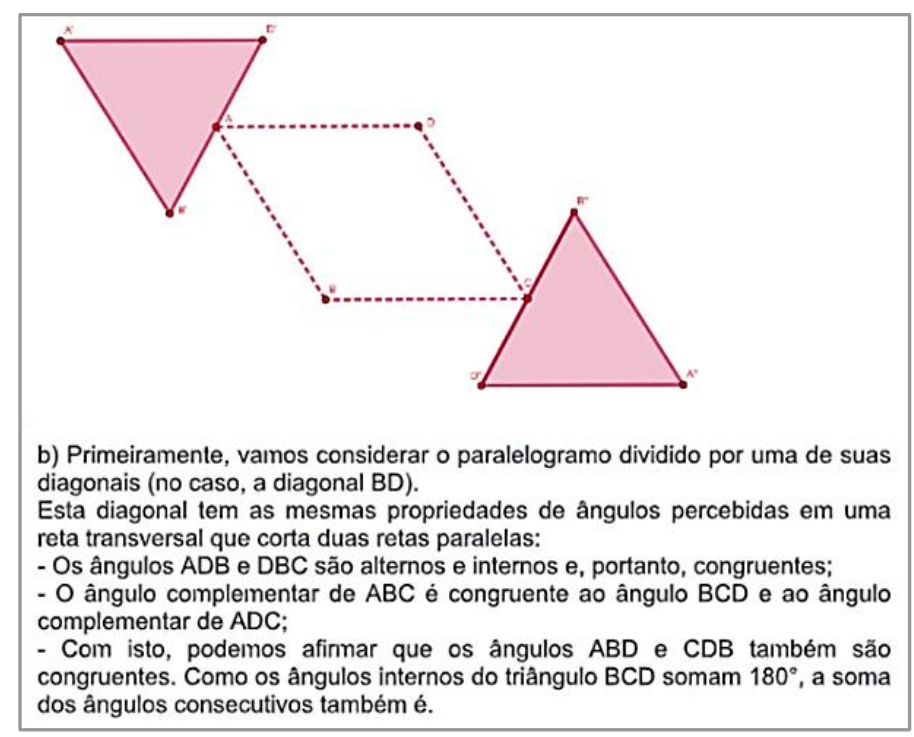

Fonte: Produção obtida no desenvolvimento do LCR (2020)

Portanto, conclui-se que o saber sobre como resolver TIGD também foi mobilizado parcialmente pelo grupo \# 3. Similar ao grupo anterior, o Excerto 3 revela que os professores não desenvolveram o processo de explorar para responder às duas primeiras questões da tarefa [2]. De fato, para responder a segunda questão foi desenvolvido o processo de generalizar, como o evidenciam as notas do grupo \# 3 [4], "pulando" o processo de experimentar, conforme também fez o grupo \# 2 (Excerto 2).

\section{Evento crítico \# 3: Uso da relação entre ângulos adjacentes para a generalização}

O último evento crítico identificado, relacionado com o saber sobre como resolver TIGD, revelou a forma como o grupo \# 1 deu resposta às questões (e) e (f) da tarefa. Basicamente, responder essas questões implicava fornecer alguma explicação ou justificação teórica geral para a propriedade geométrica abordada no decorrer do LCR. No Excerto 4, as professoras desse grupo comunicam a FP a forma como usaram a relação de adjacência entre ângulos para tal fim.

\section{Excerto 4}

1. Júlia (06:51 -07:09): A gente acabou falando o seguinte: ao traçar dois pares de retas paralelas, para representar os lados opostos do paralelogramo [refere-se às retas que contêm os lados do paralelogramo], é possível observar que o ângulo $\angle A$ [indica o ângulo $\alpha$ na tela do computador (Figura 4)], interno ao paralelogramo, e...

2. Jussara (07:14-07:18): A gente falou que esse ângulo interno [refere-se ao ângulo $\alpha$ ] se observa que é congruente ao outro [ângulo] externo [refere-se ao ângulo $\beta$ (Figura 4)].

3. FP $(07: 19-07: 20): \quad O k$ [confirma positivamente com a cabeça]. 
4. Júlia (07:21 - 07:26): E isso garante que [os ângulos] $\angle A$ e $\angle D$ [referindo-se aos ângulos $\alpha$ e $\gamma$ ] são suplementares.

5. FP (07:28 - 07:31): [Mas isso acontece] porque esses ângulos são... [refere-se aos ângulos $\beta$ e $\gamma$ ].

6. Júlia (07:31-07:32): Suplementares.

7. Jussara (07:31 - 07:32): É um ângulo raso. Soma $180^{\circ}$.

8. FP (07:33-07:36): $\quad$ Eles [refere-se aos ângulos $\beta$ e $\gamma$ ] têm outra relação. Eles são adjacentes.

9. FP (07:50 - 08:40): Então, os ângulos que possuem essa relação sempre são suplementares. Agora, essa construção é muito boa [refere-se à Figura 4] porque eu posso tirar as medidas [refere-se a não exibir a medida dos ângulos no software GeoGebra], mas a relação de posição entre eles [refere-se a $\beta$ e $\gamma$ ] sempre se mantém, de forma que o aluno poderá observar que esse ângulo sempre é raso [aquele formado pelos ângulos $\beta$ e $\gamma$ ].

No Excerto 4, Júlia inicia a explicação explicitando o traço das retas que contêm os lados do paralelogramo e coloca a atenção no ângulo $\alpha$ [1]. Jussara continua a explicação, comentando que o grupo observou que esse ângulo era congruente a $\beta$ [2], o que as levou a concluir que os ângulos $\alpha$ e $\gamma$ são suplementares [4]. Porém, apesar de confirmar o que foi dito por Jussara [2], FP detecta a falta de mais uma justificação no discurso das professoras, pelo qual orienta a atenção delas para a relação entre os ângulos $\beta$ e $\gamma$ [5]. Nesse instante, Júlia volta a afirmar que esses ângulos são suplementares [6], e isso revela não ter compreendido ainda o que FP pretende trazer à tona. Caso contrário acontece com Jussara, ao manifestar que o ângulo formado pelos ângulos $\beta$ e $\gamma$ é raso [7]. Finalmente, FP aponta que a relação entre esses ângulos é de adjacência [8] e que, devido a ser uma relação de posição entre ângulos, é possível prescindir das medidas desses objetos na construção geométrica da Figura 4 e obter, com isso, a generalidade da propriedade abordada [9].

Figura 4: Desenho utilizado pelo grupo \# 1 para justificar a propriedade geométrica

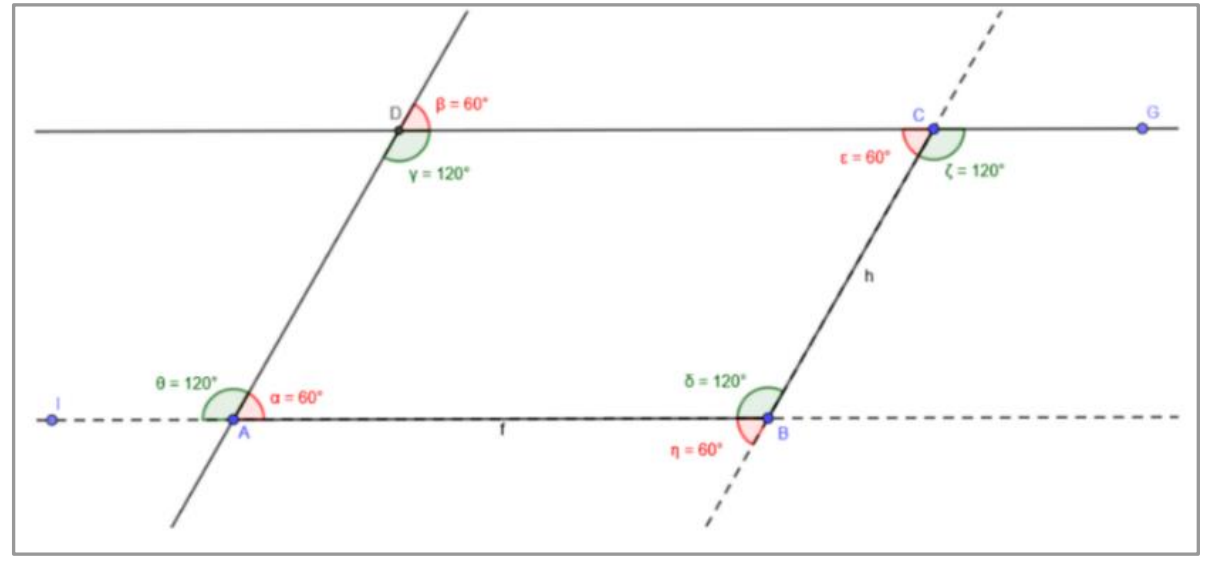

Fonte: Produção obtida no desenvolvimento do LCR (2020) 
Levando em consideração a informação do Excerto 4, pode-se observar que as professoras e FP desenvolveram, em conjunto, o último processo matemático do saber sobre como resolver TIGD: generalizar. No entanto, notou-se que as professoras, antes da intervenção de FP [5], ainda permaneciam em um estágio primário do processo de generalizar a propriedade geométrica, uma vez que seu discurso se apoiava no caso particular da relação de congruência entre os ângulos $\alpha$ e $\gamma[2,4]$ que a Figura 4 ilustra. Foi assim que FP, aproveitando o fato de as professoras terem feito referência a $\beta$, destacou que $\alpha$ e $\gamma$ são suplementares devido à relação de adjacência entre $\beta$ e $\gamma[8,9]$, sendo que $\beta \cong \alpha$, por serem ângulos consecutivos entre retas paralelas.

\section{Saber sobre como analisar TIGD}

Nesta subseção, descrevem-se os dados que dão conta da forma como os participantes mobilizaram o saber sobre como analisar TIGD, enquanto se dedicavam a responder as perguntas da tarefa ilustrada na Figura 5.

Figura 5: Tarefa de análise de TIGD

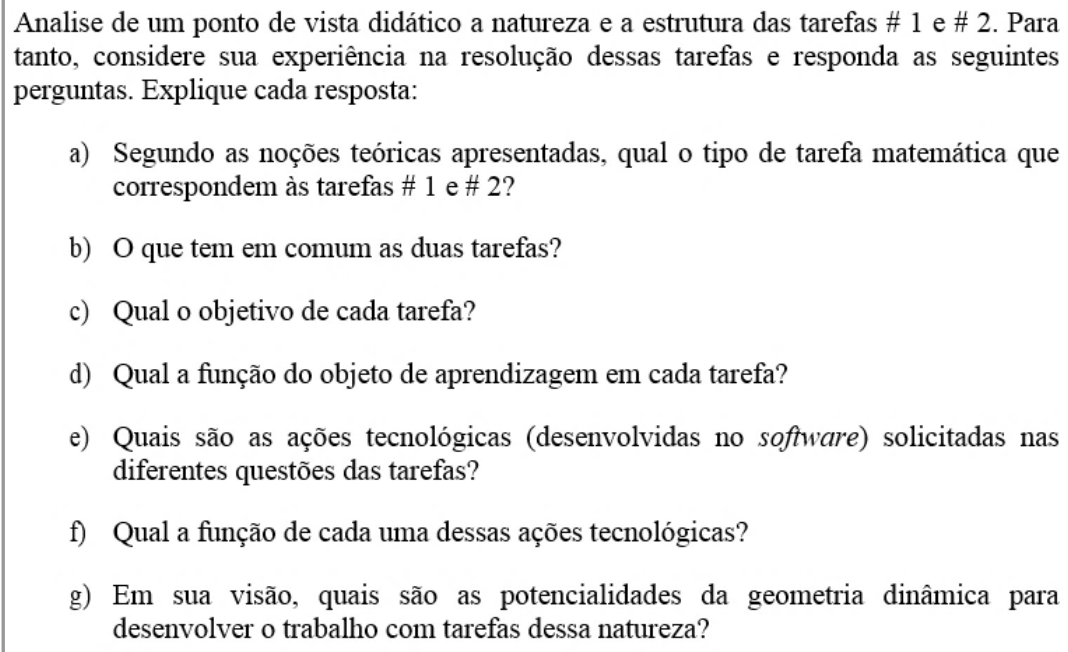

a) Segundo as noções teóricas apresentadas, qual o tipo de tarefa matemática que correspondem às tarefas \# $1 \mathrm{e} \# 2$ ?

b) $\mathrm{O}$ que tem em comum as duas tarefas?

c) Qual o objetivo de cada tarefa?

d) Qual a função do objeto de aprendizagem em cada tarefa?

e) Quais são as ações tecnológicas (desenvolvidas no software) solicitadas nas diferentes questões das tarefas?

f) Qual a função de cada uma dessas ações tecnológicas?

g) Em sua visão, quais são as potencialidades da geometria dinâmica para desenvolver o trabalho com tarefas dessa natureza?

Fonte: Elaborada pelos autores (2019)

É imperativo destacar que, antes da resolução dessa tarefa ${ }^{7,8}$, foi realizada uma discussão em plenária sobre os tipos de tarefas matemáticas implementadas no ensino de

\footnotetext{
${ }^{7}$ Considera-se que as duas tarefas apresentadas até agora são diferentes, no sentido de que os professores deviam resolver a primeira assumindo um papel de "alunos". A segunda lhes exigia "mudar" esse papel e abordá-la como "professores". Para explicitar essa mudança de papeis, solicitou-se analisar a tarefa "de um ponto de vista didático". Portanto, clarifica-se que o significado do "didático" não se refere a uma análise da tarefa visando a sua proposição como situação de ensino para um determinado grupo de alunos.

${ }^{8}$ Note-se que nesta tarefa faz-se referência a duas tarefas (\#1 e \# 2), uma vez que na formação duas foram implementadas para mobilizar o saber sobre como resolver TIGD. Por motivos de espaço, optou-se por reportar apenas os dados obtidos da análise da tarefa apresentada na subseção anterior.
} 
matemática, visando fornecer as noções teóricas para que os professores pudessem responder a primeira pergunta ilustrada na Figura 5: qual o tipo de tarefa matemática que corresponde às tarefas \# 1 e \# 2? De fato, esse momento de discussão em plenária foi suficiente para os professores responderem essa pergunta, identificando como de investigação geométrica a tarefa apresentada na subseção anterior.

Partindo desse contexto, os dois eventos críticos reportados na sequência revelam o modo como os participantes mobilizaram o saber sobre como analisar TIGD, enquanto se dedicavam a responder as perguntas restantes, ilustradas na Figura 5.

\section{Evento crítico \# 4: Reconhecimento dos processos matemáticos nas TIGD}

Este evento crítico fornece dados da forma particular em que o grupo \# 1 mobilizou o saber sobre como analisar TIGD, no que diz respeito aos processos matemáticos que caracterizam a exploração desse tipo de tarefa. Durante um tempo posterior ao início do LCA, as professoras desse grupo dedicaram-se a dar resposta à pergunta (b) da tarefa proposta, que questionava sobre aqueles aspectos que as duas TIGD previamente resolvidas tinham em comum. Após a troca de algumas ideias iniciais, as professoras chegaram às conclusões que se mostram no Excerto 5.

\section{Excerto 5}

1. Júlia (05:15 - 05:23): Sobre a estrutura [das tarefas], eu acho legal tipo colocar que as duas oferecem primeiro uma visualização de algo já pronto.

2. Aleia $(05: 24-05: 25): \quad E$.

3. Jussara (05:54-06:02): Eu acho que as duas [tarefas] iniciam pedindo para que você levante hipóteses sobre aquilo [que se observa no $\mathrm{OA}$ ].

4. Júlia (06:02-06:03): Hum rum.

5. Jussara (06:04-06:18): Então, eu acho que elas [as tarefas] já começam questionando: "o que hipótese você tem com relação a essa figura?" [refere-se à figura geométrica do OA das tarefas].

6. Júlia (06:18 - 06:19): Hum rum.

7. Jussara (06:20-06:28): Aí depois elas te levam a provar aquilo [a propriedade geométrica abordada nas tarefas]. Mas primeiro falam assim: "O que é que você acha?" Tipo: "Quais hipóteses você tem?"

No Excerto 5, Júlia inicia o diálogo, propondo aos demais membros do grupo ressaltar, como aspecto comum entre as TIGD analisadas, a visualização que os OA dessas tarefas oferecem para iniciar a sua resolução [1]. Aleia concorda [2], mas Jussara profere que, em sua opinião, as tarefas analisadas iniciam convidando o usuário a levantar hipóteses do que previamente foi visualizado no OA das tarefas [3, 5, 7]. E obtém a aprovação de Júlia 
$[4,6]$ sobre isso. Jussara finaliza sua exposição, mencionando que, após o levantamento de hipóteses, as tarefas levam o usuário a prová-las. [7].

Nesse diálogo, é possível identificar aspectos específicos que se relacionam com os processos matemáticos que caracterizam a exploração de TIGD. Um desses é o de visualização, salientado por Júlia [1]. Em relação a isso, a professora destaca que as duas TIGD analisadas “oferecem primeiro uma visualização de algo já pronto” [1]. Conforme se pode observar na sua fala, Júlia reconhece que um primeiro processo desenvolvido na resolução de TIGD é a visualização da animação reproduzida no OA das tarefas. O fato anterior vincula-se ao processo de explorar, uma vez que, com esse procedimento, os sujeitos exploram o OA da tarefa para construir imagens da situação proposta, ajudando-os a explorar visualmente essa situação e refletir sobre ela. Por sua vez, Jussara identifica dois processos, o de levantar e o de provar hipóteses [3, 5, 7]. De acordo com essa fala, o levantamento de hipóteses está em consonância com o processo matemático de conjecturar, enquanto a prova de hipóteses tem relação com o processo de generalizar.

Como se pode notar, o diálogo anterior não fornece informação de forma explícita sobre o processo de experimentar. No entanto, em um momento posterior do LCA, Júlia e Aleia fornecem mais detalhes sobre aspectos desse processo, assim como dos processos restantes, involucrados na resolução de TIGD, quando tentavam dar resposta à questão (c) da tarefa (Excerto 6).

\section{Excerto 6}

1. Aleia (10:22 - 10:43): É isso que eu colocaria aqui na (c) [(Figura 5)], que o objetivo da tarefa é que o aluno, através da visualização e da construção de ambas as tarefas, ele enxergue os conceitos... da teoria geométrica.

2. Júlia (10:44 - 12:10): Isso. Então coloca assim [começa a ditar]: "O objetivo é que o aluno perceba, através da visualização e da construção, as propriedades envolvidas naquela figura, quais os conceitos auxiliam essa percepção"... Que auxiliam nessa justificativa né? Justificativa, explicação...

3. Aleia (12:11-12:16): Não. Eu acho assim: que auxiliam na construção da teoria geométrica, que é isso que a gente quer.

4. Júlia (12:17-13:43): Então, mas isso está dentro das propriedades né, porque oh: "as propriedades envolvidas na figura" e mais, porque tipo não foi só as propriedades que a gente percebeu, mas a gente usou outros conceitos, tipo naquela hora que a gente.... Quando a gente usou, por exemplo, a mediatriz, nosso objetivo não era aprender mediatriz, mas um dos objetivos podia ser o quê? Que o aluno usasse conceitos que ele já aprendeu anteriormente... para por fim conseguir justificar aquilo né, para que ele conseguisse explicar. Porque, no fim a gente não tinha que justificar? 
5. Aleia (13:44-13:45): Sim.

6. Júlia (13:46 - 13:50): Então, tudo isso a gente fez para quê? Para conseguir justificar aquelas propriedades descobertas.

Conforme o diálogo do Excerto 6, o saber sobre como analisar TIGD está sendo mobilizado pelas professoras no momento em que se dedicam a identificar o objetivo de cada TIGD resolvida previamente. Nesse trabalho, Aleia explicita, na sua intervenção, os processos de visualização e construção, como meios para reconhecer os conceitos geométricos envolvidos nas tarefas [1]. Júlia concorda com sua colega e a convida a escrever uma resposta que inclua essas ideias, acrescentando outros conceitos que, segundo sua visão, contribuíram para justificar ou explicar as propriedades geométricas abordadas nas tarefas [2]. Nesse momento, Aleia discorda de Júlia em utilizar esses últimos termos e propõe destacar que esses conceitos "auxiliam na construção da teoria geométrica” [3]. Na sequência, Júlia interpreta que Aleia está fazendo referência às propriedades geométricas quando usa a expressão "construção da teoria geométrica", de modo que procede explicar que, além dessas propriedades, elas recorreram a outros conceitos geométricos, como a mediatriz de um segmento, para tentar justificar ou explicar as conjecturas vinculadas às propriedades $[4,6]$.

Considerando os diálogos dos Excertos 5 e 6, é possível observar que os quatro processos matemáticos (explorar, conjecturar, experimentar e generalizar) estão presentes no discurso de Júlia, Aleia e Jussara, embora com outros termos. Por exemplo, o processo de explorar emerge no discurso das professoras quando elas fazem alusão à visualização do OA. Por sua parte, o processo de conjecturar está mais presente na fala de Jussara, nos momentos em que ela menciona o levantamento de hipóteses no decorrer da resolução das TIGD. No tocante ao processo de experimentar, Aleia destaca a construção de figuras para "enxergar os conceitos", mas sem fazer destaque na medição nem no arrastar de objetos geométricos. Finalmente, o processo de generalizar emerge com maior ênfase na fala de Júlia, quando ela faz referência ao uso de conceitos auxiliares para justificar ou explicar as propriedades geométricas. De fato, essas intervenções de Júlia dão conta dos níveis 4 e 5 da profundidade matemática das tarefas de geometria dinâmica, que dizem respeito a tarefas cujos prompts requerem explicar conceitos, processos ou relações matemáticas, indo além da construção particular na tela do software, para generalizar esses aspectos (Quadro 1). 


\section{Evento crítico \# 5: Identificação das ações desenvolvidas no software GeoGebra}

Este evento crítico revela a forma com que foi mobilizado pelo grupo \# 2 o saber sobre como analisar TIGD, na tentativa de responder à questão (e) da tarefa. Para isso, os professores desse grupo deviam identificar as ações tecnológicas que eles, nas TIGD prévias, realizaram para avançar na resolução dessas tarefas. Assim, o Excerto 7 mostra o início do trabalho conjunto desses professores para responder essa questão.

\section{Excerto 7}

1. Eduardo (07:17 - 07:20): Nessas duas [tarefas] a gente só clicou na animação [dos $\mathrm{OA}]$.

2. Fábio (07:21 -07:36): Não, não, depois a gente construiu [no software] também, você está lembrado? Que a gente construiu um paralelogramo, e a gente comprovou adentro nos ângulos [refere-se à região interna do polígono] o que a gente havia levantado de hipótese na outra vez.

3. Eduardo (07:37-07:40): Ah, na tarefa passada se simulou.

4. Fábio (07:40 - 07:41): Não...

5. Eduardo (07:42-07:43): Naquela tarefa [TIGD \# 2] eu simulei tipo no quadrilátero...

6. Fábio (07:44 - 07:46): Sim, mas a gente depois construiu no GeoGebra também, você está lembrado?

7. Eduardo (07:46 - 07:48): ... [fica pensativo].

8. Fábio (07:49-07:50): Foi.

9. Eduardo (07:51 - 07:53): Não lembro... mas tudo bem, então tá...

No Excerto 7, o diálogo entre os professores revela a discordância entre eles sobre quais foram as ações tecnológicas que desenvolveram no software GeoGebra, na exploração das TIGD prévias. Nesse debate, a única ação tecnológica que houve para Eduardo foi a manipulação do OA dessas tarefas, conforme se pode ver nos momentos em que ele faz referência à animação desses recursos $[1,3,5]$. Fábio não discorda do que foi dito por Eduardo, como se pode notar quando ele diz: "sim, mas a gente depois construiu no GeoGebra também" [6]. Realmente, a origem da discordância de Fábio provém do fato de Eduardo ter dito que eles só haviam clicado na animação dos recursos [1], fazendo com que Fábio não concordasse com ele [2,4] e lembrando-lhe outras ações realizadas no software, como a construção de figuras geométricas [2, 6]. Aliás, no discurso de Fábio está implícita outra ação tecnológica, a medição, quando faz referência ao fato de ter usado a construção do paralelogramo da TIGD \# 1 para testar, “adentro nos ângulos”, a hipótese levantada [2].

As intervenções de Fábio deixam dúvidas em Eduardo [7] que, ato seguido, reconhece não lembrar o dito pelo seu colega [9]. Fábio, perante as dúvidas de Eduardo, 
recorre ao processo de construção do paralelogramo da TIGD inicial (Figura 1), para ajudálo a recordar as ações tecnológicas que eles desenvolveram no software, após a manipulação do OA das tarefas (Excerto 8).

\section{Excerto 8}

1. Fábio (07:54-08:04): Lembra que assim, oh, foi que a gente utilizou... A gente fez a paralela: fizemos um ponto, lembra?

2. Eduardo (08:05 - 08:06): Sim, recordo bem.

3. Fábio (08:05 - 08:06): Depois a gente fez a paralela.

4. Eduardo (08:06-08:07): Sim, igual eu lembro.

5. Fábio (08:07-08:09): A gente colocou dois pontos separados e construiu o paralelogramo.

6. Eduardo (08:09-08:10): Certo.

7. Fábio (08:10-08:20): E aí a gente colocou os ângulos dentro para poder comprovar que após a movimentação [do desenho no software] permaneciam os ângulos, lembra? Que a gente até comprovou nos ângulos [refere-se à propriedade geométrica abordada].

8. Eduardo (08:21 - 08:23): É, mas eu estava focado na simulação [do OA]...

9. Fábio (08:23-08:38): Aaahh, entendi. Não, é que a tarefa, aqui nesse caso, está sendo considerada como um todo, desde o ponto de partida da animação [do OA], até exatamente a construção final.

De acordo com o Excerto 8, Eduardo relembra as ações tecnológicas que Fábio salienta $[2,4,6]$, à medida que este último desenvolve sua intervenção em torno da construção e da manipulação de um paralelogramo na interface do software GeoGebra [1, 3, 5, 7]. Finalmente, Eduardo toma consciência dessas ações, ao reconhecer que ele "estava focado na simulação" do OA das TIGD [8]. Em outras palavras, Eduardo acreditava que a resposta à questão (e) da tarefa (Figura 5) só se limitava a identificar as ações tecnológicas vinculadas à exploração inicial dos OA das TIGD, o que levou Fábio a esclarecer-lhe que, segundo o solicitado pela tarefa, devia informar-se sobre todas as ações tecnológicas realizadas no software, "desde o ponto de partida da animação, até exatamente a construção final" [9].

Em síntese, este evento crítico revela a forma como Eduardo e Fábio, mediante uma discussão que envolveu o confronto de opiniões, identificaram as ações tecnológicas desenvolvidas no software GeoGebra. Uma dessas ações é a de construir, trazida à tona por Fábio nos momentos em que enfatizava a construção do paralelogramo da TIGD \# 1 [5]. Uma segunda ação tecnológica destacada foi a medição de objetos geométricos, mesmo sem ser referida assim explicitamente, quando Fábio menciona a Eduardo o fato de eles terem colocado "os ângulos dentro" do paralelogramo [7]. Na mesma linha, Fábio destaca o arrastar de objetos geométricos como uma terceira ação tecnológica, quando se refere à 
"movimentação" do paralelogramo construído para o posterior teste da propriedade geométrica abordada [7]. Portanto, conforme pode constatar-se, essas ações tecnológicas que emergiram na discussão entre Eduardo e Fábio têm relação direta com as ações sublinhadas ao longo de cada prompt do marco para a análise de tarefas de geometria dinâmica (Quadro 1) e que caracterizam a exploração desse tipo de tarefa (como é o caso das TIGD).

\section{Saber sobre como elaborar TIGD}

Para finalizar com a descrição dos dados, nesta subseção reportam-se os resultados sobre a forma com que o saber sobre como elaborar TIGD foi mobilizado. Visando à mobilização desse saber, os professores foram convidados a elaborar uma TIGD para o ensino de geometria, segundo a experiência prévia com as tarefas anteriormente resolvidas no curso de extensão.

Figura 6: TIGD elaborada pelo grupo \# 3

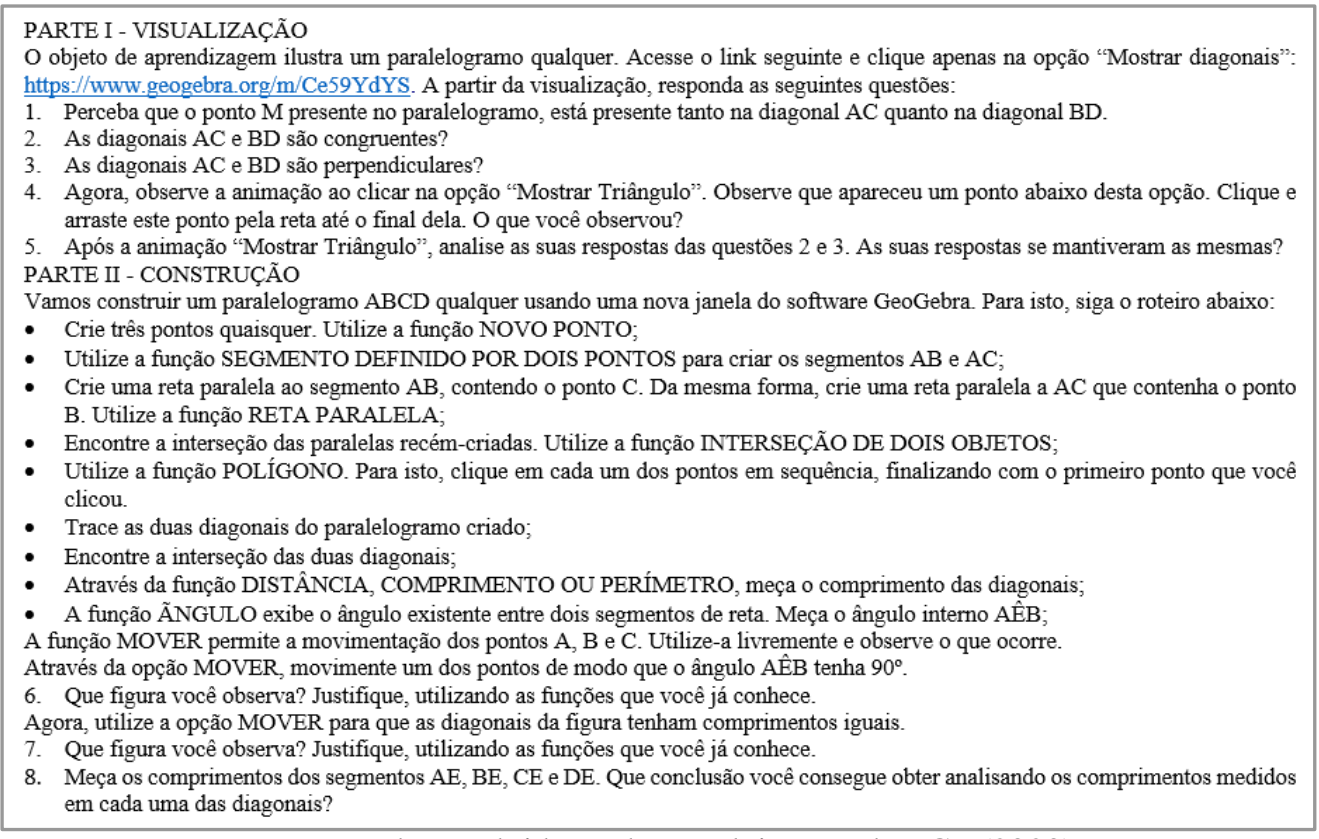

Fonte: Produção obtida no desenvolvimento do LCE (2020)

Dentre as orientações dessa tarefa, os professores deviam selecionar uma de oito propriedades geométricas previamente indicadas por FP para, posteriormente, explorar um OA vinculado a cada propriedade. Cada OA sugerido foi recuperado na internet, e sua escolha respondeu às possibilidades que esses recursos ofereciam de iniciar investigações geométricas das propriedades indicadas. Após explorarem o recurso correspondente, os professores deviam formular questões que levassem ao desenvolvimento da investigação da propriedade geométrica selecionada. 
Na sequência é descrito o caso do grupo \# 3, que decidiu elaborar uma TIGD para a investigação da seguinte propriedade geométrica: as diagonais de qualquer paralelogramo se interceptam no ponto médio delas ${ }^{9}$. Sobre este caso, é importante comentar que o procedimento metodológico seguido para a análise dos dados foi diferente do apresentado até agora: os eventos críticos desta subseção foram identificados na TIGD elaborada pelo grupo (Figura 6). Isso implica dizer que "eventos críticos não são apenas identificados nas gravações de vídeo. Os pesquisadores podem encontrar eventos críticos fora do vídeo, em materiais como as anotações dos estudantes ou nas proposições escritas em um diário do estudante" (Powell et al., 2004, p. 23). Em seguida, esses autores acrescentam: “[...] os pesquisadores podem revisar as gravações de vídeo para localizar eventos anteriores que explicam o evento crítico identificado" (p. 23).

Decidiu-se mencionar o conteúdo dessa TIGD porque foi possível reconhecer aspectos relevantes que possuem relação com a questão da pesquisa. Assim sendo, a seguir serão descritos os dois eventos críticos identificados na TIGD elaborada pelo grupo \# 3 .

\section{Evento crítico \# 6: Formulação explícita de mais de uma investigação geométrica}

Conforme a Figura 6, a tarefa elaborada pelo grupo \# 3 possui uma estrutura que visa ao desenvolvimento de uma investigação geométrica com o software GeoGebra, mediante o desdobramento dos processos matemáticos explorar, conjecturar, experimentar e generalizar, característicos do saber sobre a forma de resolver TIGD. No entanto, a tarefa elaborada pelos professores possui um aspecto que difere das TIGD resolvidas previamente no curso de extensão, que tem a ver com a formulação explícita de investigações geométricas adicionais à principal. Especificamente, trata-se da investigação do fato de as diagonais: (i) de um losango serem perpendiculares e (ii) de um retângulo serem congruentes.

Entende-se que essas investigações são adicionais porque o OA utilizado foi elaborado para investigar a propriedade geométrica inicialmente selecionada (as diagonais de qualquer paralelogramo se interceptam no ponto médio delas). No Excerto 9, Carla explica, em representação do seu grupo, as razões de acrescentar essas investigações na tarefa, no momento de discussão em plenária do LCE desenvolvido.

\footnotetext{
${ }^{9} \mathrm{O}$ OA vinculado a essa tarefa pode ser acessado no endereço: https://www.geogebra.org/m/Ce59YdYS.
} 


\section{Excerto 9}

1. Carla (02:15-03:53): A nossa ideia foi a seguinte. A partir dessa construção [o paralelogramo no software], ele [o aluno] já concluiu que as diagonais se intersectam no ponto médio, a gente pensou em fazer com que ele movesse a figura e conseguisse fazer com que $o$ ângulo [entre as diagonais do paralelogramo] fosse de $90^{\circ}$. Porque ele vai medir o ângulo e não vai dar $90^{\circ}$. Então tentar mover [o polígono] para obter os $90^{\circ}$, para ver se ele consegue visualizar o losango... Então ele vai concluir o quê? Que no losango as diagonais são perpendiculares, mas não congruentes... A gente até tentou fazer a conjunção das duas figuras [losango e retângulo]... para mostrar que as diagonais congruentes e perpendiculares resultam no quadrado... Então a ideia é mostrar isso, porque muitas vezes é ensinado que retângulo é retângulo, quadrado é quadrado e losango é losango né. Então, através dessa tarefa, a partir de um paralelogramo qualquer, é possível fazer perceber que um retângulo é paralelogramo, que um losango é quadrado, e o mais importante, mostrar que o quadrado é tanto retângulo quanto losango.

A fala de Carla no Excerto 9 revela duas razões para acrescentar as investigações mencionadas à TIGD elaborada. De um lado, observa-se que o grupo \# 3 identificou a oportunidade de investigar, a partir da exploração do OA, o fato de as diagonais de um losango serem perpendiculares e as de um retângulo serem congruentes. Para tal, Carla explicita o desenvolvimento de um conjunto de ações tecnológicas, como medir o ângulo entre as diagonais de um paralelogramo construído no software, ou arrastar o quadrilátero ao longo da tela do computador para o aluno obter configurações específicas desse polígono, que o levem a conjecturar as propriedades geométricas citadas. De outro lado, a professora menciona a ideia de estabelecer relações entre os diferentes tipos de paralelogramos (retângulo, losango e quadrado), "para mostrar que as diagonais congruentes $e$ perpendiculares resultam no quadrado" [1].

Nota-se que a informação contida na Figura 6 e no Excerto 9 evidencia como o grupo \# 3 considerou, no momento de elaborar a tarefa, vários aspectos que caracterizam a exploração de TIGD. Um desses aspectos é a possibilidade de elaborar novos tipos de problemas. Com efeito, e conforme já foi destacado, as duas investigações acrescentadas sobre o losango e o retângulo foram pensadas pelos professores para ser decorrentes do trabalho investigativo dos alunos, no que tange à propriedade geométrica inicial. Com esses novos tipos de problemas seria possível promover outro aspecto das TIGD, como a manipulação dinâmica de objetos construídos, nos momentos em que os alunos forem convidados a deslocar o paralelogramo previamente obtido para a geração de conjecturas 
sobre a perpendicularidade e a congruência das diagonais desse quadrilátero, e o reconhecimento dos vínculos entre essas características e o tipo de paralelogramo formado na tela do computador.

\section{Evento crítico \# 7: Entrega do roteiro de construção das figuras geométricas}

Este último evento crítico revela um aspecto da TIGD elaborada pelo grupo \# 3 que, similar ao caso anterior, é considerado diferenciador com respeito às TIGD resolvidas ao longo do curso de extensão. Esse aspecto tem a ver com o fato de os professores desse grupo fornecerem o roteiro de construção das figuras geométricas, no momento de desenvolver o processo de experimentação com o software GeoGebra para o teste das conjecturas previamente estabelecidas. No Excerto 10, FP destaca esse fato no momento em que o grupo \# 3 apresenta a tarefa elaborada para o resto de colegas [1]. Segundos posteriores, Carla intervém novamente para explicar a razão de fornecer o roteiro das construções geométricas na proposta da tarefa.

\section{Excerto 10}

1. FP (04:30 - 05:14): $\quad$ Eu vejo, na tarefa de vocês, alguns aspectos interessantes... Um deles tem a ver com o roteiro das construções...

2. Carla (05:45-06:26): A gente pensou mais na visualização [do que no processo de construção], porque a gente que dá aula percebe que, se você desenhar um quadrado, o aluno vai falar que não é retângulo. Então a gente achou que se poderia aproveitar essa tarefa para mostrar essas coisas, para que ele visualize. A gente achou que isso é a parte mais importante para ele. Porque o que é um paralelogramo ele sabe, um retângulo ele sabe, mas mostrar que o quadrado é um caso particular deles [retângulo e losango] para os alunos é difícil, por mais que a gente trabalhe com isso. Se o quadrado não estiver na posição quando os lados são verticais e horizontais, então ele acha que não é [quadrado]. Se o losango não estiver na posição bandeirinha do amarelo da bandeira do Brasil, então não é [losango].

Conforme o Excerto 10, a razão exposta por Carla tem relação direta com o evento crítico anterior, no que tange ao fato de aproveitar as possibilidades que o software GeoGebra oferece para visualizar as relações entre os diferentes tipos de paralelogramos. Com efeito, Carla expõe que o seu grupo dedicou mais importância à parte visual da tarefa, em detrimento do próprio processo de construção das figuras geométricas, levando em consideração as dificuldades que comumente os alunos possuem para relacionar esses tipos de paralelogramos, bem como para identificá-los quando a sua configuração gráfica não é prototípica. Em relação a isso, ela disse: "Se o quadrado não estiver na posição quando os 
lados são verticais e horizontais, então ele acha que não é. Se o losango não estiver na posição bandeirinha do amarelo da bandeira do Brasil, então não é” [2].

De acordo com as razões expostas por Carla, é possível identificar na TIGD elaborada pelo seu grupo outros aspectos que caracterizam o trabalho com tarefas de geometria dinâmica de cunho investigativo. Esses aspectos se referem à possibilidade de realizar o teste de conjecturas matemáticas usando um grande número de exemplos e de convencimento da veracidade dessas conjecturas. De fato, a fala de Carla revela a intenção do seu grupo de aproveitar os benefícios que o software GeoGebra oferece para criar um ambiente de experimentação dinâmica, em que o aluno possa manipular e modificar a configuração gráfica de um paralelogramo qualquer mediante a função de arrastar, a fim de visualizar e convencer-se das relações geométricas antes mencionadas para os muitos casos que se observarem na tela do computador, relações que "para os alunos é difícil, por mais que a gente trabalhe com isso" [2].

Considerando o comunicado nesta seção, a seguir será realizada uma discussão dos resultados obtidos e serão formuladas as conclusões da pesquisa.

\section{Discussão e conclusões}

O objetivo do artigo foi analisar a forma como um grupo de professores de matemática, em um contexto de formação continuada, mobilizou saberes vinculados à resolução, à análise e à elaboração de tarefas investigativas de geometria dinâmica para o ensino de geometria na educação básica. Para atingir esse objetivo, foi empregado um procedimento metodológico que permitiu identificar e examinar sete eventos críticos no decorrer das diferentes atividades, no intuito de revelar a forma com que os saberes sobre como resolver, analisar e elaborar TIGD foram mobilizados na pesquisa. Após a análise e descrição dos dados, formulam-se as seguintes conclusões.

Em primeiro lugar, os resultados revelaram que o saber sobre como resolver TIGD foi mobilizado por um grupo de professores e "parcialmente" pelos outros. No primeiro caso, os eventos críticos \# 1 e \# 3 mostraram que as professoras do grupo \# 1 conseguiram desenvolver os processos de explorar, conjecturar, experimentar e generalizar (Christou et al., 2005), fornecendo raciocínios decorrentes tanto da manipulação do OA quanto das respostas a cada prompt da tarefa. Entretanto, estas professoras apresentaram dificuldades para concretizar o processo de generalizar, já que o desenho usado para apoiar o seu 
raciocínio ilustrava as medidas numéricas dos ângulos da situação, fato que lhes impedia ir além dessa particularidade. No segundo caso, o evento crítico \# 2 revelou que os grupos \# 2 e \# 3 não mobilizaram o saber do modo esperado, uma vez que os professores omitiram os processos de explorar e experimentar com o software GeoGebra no LCR, dedicando-se a conjecturar e generalizar a propriedade geométrica usando raciocínio dedutivo.

Em segundo lugar, os dados descritos mostraram que os professores mobilizaram o saber sobre como analisar TIGD mediante interações baseadas no diálogo, conforme os eventos críticos \# 4 e \# 5. Por um lado, o evento \# 4 revelou que os quatro processos matemáticos anteriores foram identificados pelas professoras do grupo \# 1, usando expressões familiares para elas e que possuem vínculos com os diferentes níveis dos domínios do marco de análise usado na pesquisa (Trocki \& Hollebrands, 2018). Assim, o processo de explorar emergiu no LCA das professoras ao fazerem referência à visualização do OA. Por sua parte, o processo de conjecturar se manifestou nos momentos em que se fazia alusão ao levantamento de hipóteses. No tocante ao processo de experimentar, destacou-se o uso de expressões como "enxergar os conceitos”. Finalmente, o processo de generalizar emergiu quando se fazia referência ao uso de conceitos auxiliares para justificar ou explicar as propriedades geométricas abordadas. Por outro lado, no evento \# 5 aconteceu algo similar no LCA dos professores do grupo \# 2, os quais usaram expressões como "os ângulos dentro" e "movimentação" para explicitar as ações tecnológicas de medir e arrastar objetos geométricos em um SGD.

Em terceiro lugar, os resultados revelaram que o saber sobre como elaborar TIGD foi mobilizado em função da atuação dos professores do grupo \# 3 enquanto profissionais da educação. Os eventos críticos \# 6 e \# 7 mostraram que esses professores decidiram formular mais de uma investigação geométrica e entregar o roteiro de construções na tarefa elaborada por eles. Essas duas ações evidenciam aspectos característicos da exploração de TIGD (Borba et al., 2018), como as possibilidades de: (i) elaborar novos tipos de problemas - investigações sobre o losango e o retângulo; (ii) manipular dinamicamente objetos construídos - ao deslocar o paralelogramo inicial da tarefa; (iii) gerar conjecturas - sobre a perpendicularidade e a congruência das diagonais desse quadrilátero; (iv) realizar testes de conjecturas matemáticas usando um grande número de exemplos; e (v) convencer sobre a veracidade de conjecturas formuladas.

Finalmente, conclui-se que a forma como esses três saberes foram mobilizados na pesquisa viu-se influenciada por três aspectos: (i) as interações entre os participantes; (ii) a 
relação entre os professores e o software GeoGebra; e (iii) a relação entre os professores e os saberes. Na sequência serão discutidos esses aspectos.

\section{As interações entre os participantes}

Os resultados da pesquisa permitem concluir que a forma como os participantes mobilizaram os três saberes esteve em correspondência com o tipo de interação entre eles, no decorrer das atividades do curso de extensão. Com relação a isso, percebe-se nos dados a intenção de FP de criar no contexto formativo um ambiente em que fosse possível desenvolver um labor conjunto, em que tanto ele quanto os professores tivessem protagonismo na concretização do trabalho comum que os unia.

Evidências do fato anterior encontram-se no conteúdo dos Excertos 2, 3 e 4, nos quais se mostra como as interações entre FP e professores influenciaram o desenvolvimento do trabalho comum do LCR. Por um lado, nos Excertos 2 e 3 é possível observar o esforço de FP para fazer com que os professores compreendessem a importância de reconhecer o papel do OA e as possibilidades fornecidas por esse recurso para ajudar a visualizar dinamicamente a propriedade geométrica da tarefa, e não simplesmente conjecturar a respeito dela. Por outro lado, o Excerto 4 mostra como FP: (i) identifica o fato de as professoras ainda não haverem concretizado o passo final da sua investigação, que lhes permitisse generalizar a propriedade geométrica abordada; e (ii) intervém para ajudá-las a concretizar esse passo. Essas formas de interação manifestadas por FP nos excertos indicados revela o compromisso que ele tinha com os professores de contribuir na produção do trabalho comum deles (Radford, 2020).

No entanto, outro tipo de interação que vale a pena destacar foi a manifestada pelos próprios professores, enquanto esses se encontravam engajados em resolver as tarefas propostas. No tocante a isso, destacam-se os excertos do evento crítico \# 5, nos quais se mostram os diálogos que Eduardo e Fábio estabeleceram enquanto se dedicavam a identificar as ações tecnológicas presentes nas TIGD resolvidas previamente. Especificamente, a forma de interação manifestada por Fábio no Excerto 8 revela, nos termos de Radford (2020), a responsabilidade com que ele agiu para ajudar Eduardo a recordar as ações tecnológicas que ele mesmo reconheceu ter esquecido (Excerto 7). 


\section{A relação entre os professores e o software GeoGebra}

Os resultados da pesquisa também permitem concluir que a maneira como os professores estabeleceram relação com o software GeoGebra influenciou a forma como os três saberes profissionais foram mobilizados. Com efeito, os dados descritos revelam que as ações e as decisões dos professores no desdobramento das atividades estiveram em correspondência com o modo como eles usaram o software para concretizar o seu trabalho comum. No tocante a esse ponto, destaca-se o caso do grupo \# 3 e sua evolução na apropriação desse artefato tecnológico ao longo do curso de extensão.

Em relação a isso, no evento crítico \# 2 reportou-se o fato de esse grupo de professores não fornecer respostas às primeiras questões da tarefa proposta, que fossem reveladoras de um verdadeiro uso do OA correspondente. Pelo contrário, conforme o ilustra a Figura 3, o grupo \# 3 recorreu a uma explicação voltada ao plano teórico para justificar a propriedade geométrica visualizada na reprodução da animação desse recurso, embora a representação gráfica dessa animação tivesse sido usada para "apoiar" essa explicação. Esse uso que o grupo \# 3 deu ao recurso tecnológico é um exemplo do que Borba et al. (2018) chamam de domesticação de uma TD. O fato anterior pode explicar-se por meio dos resultados da pesquisa empírica realizada por Acosta (2010), os quais revelaram como um grupo de professores de matemática, participantes de um curso de formação continuada, teve dificuldades para resolver um conjunto de tarefas de geometria dinâmica, uma vez que as praxeologias $^{10}$ estáticas desenvolvidas por eles entraram em conflito com as praxeologias dinâmicas que efetivamente deviam de ser desdobradas.

No entanto, conforme foi avançando o curso de extensão, os professores do grupo \# 3 foram apropriando-se do software GeoGebra no que tange às possibilidades que esse artefato oferece para manipular desenhos geométricos na tela do computador e visualizar relações geométricas entre polígonos de uma mesma classe, como o paralelogramo, e a relação entre retângulo, losango e quadrado (ver eventos críticos \# 6 e \# 7).

\section{A relação entre os professores e os saberes}

Finalmente, os dados da pesquisa mostram que a relação entre os professores e o saber sobre como elaborar TIGD teve influência na maneira com que esse saber foi mobilizado no curso de extensão. De fato, a informação fornecida nos eventos críticos \# 6 e

\footnotetext{
${ }^{10}$ Conceito usado na Didática Francesa para fazer referência à matemática como uma prática humana.
} 
\# 7 revela como essa relação foi mediada pelas experiências profissionais dos professores em seus contextos de trabalho, o que os levou a pensar e elaborar uma TIGD (Figura 6) que respondesse às suas necessidades de ensino e às possibilidades de aprendizagem de seus alunos. Esse fato dialoga com o pensamento de Tardif (2014) sobre que os saberes dos professores devem ser compreendidos em íntima relação com o trabalho deles em sala de aula. Sobre essa ideia, o referido autor profere que os professores utilizam diferentes saberes "em função do seu trabalho e das situações, condicionamentos e recursos ligados a esse trabalho. Em suma, o saber está a serviço do trabalho [...]. O saber do professor traz em si mesmo as marcas de seu trabalho" (p. 17).

A pesquisa reportada neste artigo fornece informação empírica sobre a forma com que três saberes profissionais foram mobilizados em um contexto de formação continuada de professores que ensinam matemática, baseado no uso de SGD para o ensino de geometria na educação básica. Entretanto, no que tange a pesquisas futuras, considera-se importante realizar estudos relacionados com a temática abordada, em que se investiguem, por exemplo, as formas como professores que ensinam matemática desenvolvem aprendizagem profissional, quando se envolvem de forma conjunta, emocional e ética em atividades formativas como as descritas neste artigo.

\section{Agradecimentos}

O presente trabalho foi realizado com apoio da Coordenação de Aperfeiçoamento de Pessoal de Nível Superior - Brasil (CAPES) - Código de Financiamento 001

\section{Referências}

Acosta G., M. E. (2010). Dificultades de los profesores para integrar el uso de Cabri en clase de geometría. Experiencias de un curso de formación docente. Tecné, Episteme y Didaxis: TED, (28), 57-72. https://doi.org/10.17227/ted.num28-1074.

Arzarello, F., Olivero, F., Paola, D. \& Robutti, O. (2002). A cognitive analysis of dragging practises in Cabri environments. Zentralblatt fur Didaktik der Mathematik, 34(3), 66-72. http://dx.doi.org/10.1007/BF02655708.

Bogdan, R. C. \& Biklen, S. K. (1994). Investigação qualitativa em educação: Uma introdução à teoria e aos métodos. Porto Editora.

Borba, M. C., Silva, R. S. \& Gadanidis, G. (2018). Fases das tecnologias digitais em Educação Matemática (2.a edição). Autêntica Editora. (Original publicado em 2014).

Brasil. (2017). Base nacional curricular comum - BNCC (Ensino Fundamental). Ministério da Educação. 
Brocardo, J. (2014). Tarefas matemáticas. Em L. Santos (Ed.), Investigação em Educação Matemática 2014: Tarefas matemáticas (pp. 3-4). Sociedade Portuguesa de Investigação em Educação Matemática.

Christou, C., Mousoulides, N., Pittalis, M. \& Pitta-Pantazi, D. (2005). Problem solving and problem posing in a dynamic geometry environment. The Mathematics Enthusiast, 2(2), 125-143. https://scholarworks.umt.edu/tme.

Cyrino, M. C. C. T. \& Jesus, C. C. (2014). Análise de tarefas matemáticas em uma proposta de formação continuada de professoras que ensinam matemática. Ciência e Educação, 20(3), 751-764. http://dx.doi.org/10.1590/1516-73132014000300015.

Delgado, C. (2014). Práticas de seleção/construção e preparação de tarefas que visam o desenvolvimento do sentido de número. Em L. Santos (Ed.), Investigação em Educação Matemática 2014: Tarefas Matemáticas (pp. 27-55). Sociedade Portuguesa de Investigação em Educação Matemática.

Fiorentini, D. \& Lorenzato, S. (2012). Investigação em Educação Matemática: Percursos teóricos e metodológicos (3.a edição). Autores Associados. (Original publicado em 2006).

Gutiérrez, R. E. \& Pazuch, V. (2019). Tarefas de geometria dinâmica com objetos de aprendizagem para a exploração e a investigação de conceitos geométricos. Boletim GEPEM, (74), 20-36. http://costalima.ufrrj.br/index.php/gepem/article/view/264.

Kalinke, M. A., Derossi, B., Janegitz, L. E. \& Ribeiro, M. S. N. (2015). Tecnologias e educação matemática: Um enfoque em lousas digitais e objetos de aprendizagem. Em M. A. Kalinke e L. F. Mocrosky (Eds.), Educação matemática: Pesquisas e possibilidades (pp. 159-186). Editora UTFPR.

Marrades, R. \& Gutiérrez, A. (2000). Proofs produced by secondary school students learning geometry in a dynamic computer environment. Educational Studies in Mathematics, 44(1-3), 87-125. https://doi.org/10.1023/A:1012785106627.

Moretti, V. D. \& Moura, M. O. (2011). Professores de matemática em atividade de ensino: Contribuições da perspectiva histórico-cultural para a formação docente. Ciência $e$ Educação, 17(2), 435-450. https://doi.org/10.1590/S1516-73132011000200012.

National Council of Teachers of Mathematics (2000). Principles and standards for school mathematics. Author.

Ponte, J. P. (2003). Investigação sobre investigações matemáticas em Portugal. Investigar em educação, 2, 93-169.

Ponte, J. P. (2012). Estudiando el conocimiento y el desarrollo profesional del profesorado de matemáticas. En N. Planas (Ed.), Teoría, crítica y práctica de la educación matemática (pp. 83-98). Graó.

Ponte, J. P., Brocardo, J. \& Oliveira, H. (2016). Investigações matemáticas na sala de aula (3.a edição). Autêntica Editora. (Original publicado em 2003).

Powell, A. B., Francisco, J. M. \& Maher, C. A. (2004). Uma abordagem à análise de dados de vídeo para investigar o desenvolvimento das ideias matemáticas e do raciocínio de estudantes. Bolema: Boletim de Educação Matemática, 17(21), 81-140. http://www.periodicos.rc.biblioteca.unesp.br/index.php/bolema/article/view/10538. 
Prieto, J. L. \& Valls, J. (2010). Aprendizaje de las características de los problemas aritméticos elementales de estructura aditiva en estudiantes para maestro. Educación Matemática, 22(1), 57-85. http://somidem.com.mx/revista/vol22-1/.

Radford, L. (2014, 18 de outubro). La enseñanza-aprendizaje desde una perspectiva histórico-cultural: La Teoría de la Objetivación [vídeo]. https://www.luisradford.ca/pub/video_gemad_Oct18_2014.html.

Radford, L. (2017a). Aprendizaje desde la perspectiva de la Teoría de la Objetivación. En B. D' Amore y L. Radford (Eds.), Enseñanza y aprendizaje de las matemáticas: Problemas semióticos, epistemológicos y prácticos (pp. 115-136). Universidad Distrital Francisco José de Caldas.

Radford, L. (2017b). A Teoria da Objetivação e seu lugar na pesquisa sociocultural em educação matemática. Em V. D. Moretti e W. L. Cedro (Eds.), Educação Matemática e a teoria histórico-cultural (pp. 229-261). Mercado de letras.

Radford, L. (2017c). Saber y conocimiento desde la perspectiva de la Teoría de la Objetivación. En B. D’ Amore y L. Radford (Eds.), Enseñanza y aprendizaje de las matemáticas: Problemas semióticos, epistemológicos y prácticos (pp. 97-114). Universidad Distrital Francisco José de Caldas.

Radford, L. (2020). Un recorrido a través de la Teoría de la Objetivación. Em S. TakecoGobara e L. Radford (Eds.), Teoria da Objetivação: Fundamentos e aplicações para o ensino e aprendizagem de ciências e matemática (pp. 15-42). Livraria da Física.

Rojano, T. (2014). El futuro de las tecnologías digitales en la educación matemática: Prospectiva a 30 años de investigación intensiva en el campo. Educación Matemática, 26(Número Especial), 11-30. https://bit.ly/3atG7JS.

Serrazina, M. L. M. (2012). Conhecimento matemático para ensinar: Papel da planificação e da reflexão na formação de professores. Revista Eletrônica de Educação, 6(1), 266283. http://dx.doi.org/10.14244/19827199355.

Steele, D. F. (2001). Vozes entusiastas de jovens matemáticos. Educação e Matemática, (62), 39-42. http://www.apm.pt/apm/revista/educ62/educ62.htm.

Stein, M. K. \& Smith, M. S. (2009). Tarefas matemáticas como quadro para a reflexão. Educação e Matemática, (105), 22-28. https://bit.ly/2VZe5Rq.

Stein, M. K., Smith, M. S., Henningsen, M. A. \& Silver, E. A. (2009). Implementing standards-based mathematics instruction: A casebook for professional development. Teachers College Press.

Tardif, M. (2014). Saberes docentes e formação profissional (17.a edição). Editora Vozes. (Original publicado em 2002).

Trocki, A. \& Hollebrands, K. (2018). The development of a framework for assessing dynamic geometry task quality. Digital Experiences in Mathematics Education, 4(2-3), 110-138. https://doi.org/10.1007/s40751-018-0041-8.

Valente, W. R. (2017). A matemática a ensinar e a matemática para ensinar: Os saberes para a formação do educador matemático. Em R. Hofstetter e W. R. Valente (Eds.), Saberes em (trans)formação: Tema central da formação de professores (pp. 201-228). Livraria da Física.

Vieira, A. F., Trevisan, A. L., Baldini, L. A. \& Rocha, Z. F. (2018). Conhecimentos mobilizados por uma professora no delineamento de uma tarefa matemática. Educação 
$\begin{array}{llllll}\text { Matemática em } & \text { Revista } & - & R S, & 2(19), & 144-153 .\end{array}$ http://www.sbem.com.br/revista/index.php/EMR-RS/article/view/1797.

Yeo, J. B. W. (2007). Mathematical tasks: Clarification, classification and choice of suitable tasks for different types of learning and assessment. Mathematics and Mathematics Education, 1-26. http://hdl.handle.net/10497/949.

Autores

Rafael Enrique Gutiérrez Araujo Mestre em Ensino e História das Ciências e da Matemática pela Universidade Federal do ABC (Brasil). Coordenador de Formação da Asociación Aprender en Red (Venezuela). Temas de pesquisa: Formação de professores que ensinam matemática; Saberes docentes; Tecnologias digitais no ensino de geometria. E-mail: rafael.gutierrez0593@gmail.com

Vinícius Pazuch

Doutor em Ensino de Ciências e Matemática pela Universidade Luterana do Brasil. Professor Adjunto do Centro de Matemática, Computação e Cognição (CMCC) da Universidade Federal do ABC (Brasil). Temas de pesquisa: Processos formativos (formação inicial e continuada); Conhecimento profissional docente; Ensino de geometria; Tecnologias digitais. E-mail: vinicius.pazuch@ufabc.edu.br 